\title{
JOSANA KAPRONEZAI
}

Estudo de provas microbiológicas e celulares em amostras de leite provenientes de fêmeas bubalinas (Bubalus bubalis) no Estado de São Paulo 


\title{
JOSANA KAPRONEZAI
}

\section{Estudo de provas microbiológicas e celulares em amostras de leite provenientes de fêmeas bubalinas (Bubalus bubalis) no Estado de São Paulo}

\author{
Dissertação apresentada ao programa de Pós- \\ graduação em Epidemiologia Experimental e \\ Aplicada às Zoonoses da Faculdade de Medicina \\ Veterinária e Zootecnia da Universidade de São \\ Paulo para a obtenção do título de Mestre em \\ Medicina Veterinária \\ Departamento: \\ Medicina Veterinária Preventiva e Saúde animal \\ Área de concentração: \\ Epidemiologia Experimental e Aplicada às \\ Zoonoses \\ Orientador: \\ Prof. Dr. Nilson Roberti Benites
}


Autorizo a reprodução parcial ou total desta obra, para fins acadêmicos, desde que citada a fonte.

DADOS INTERNACIONAIS DE CATALOGAÇÃO-NA-PUBLICAÇÃO

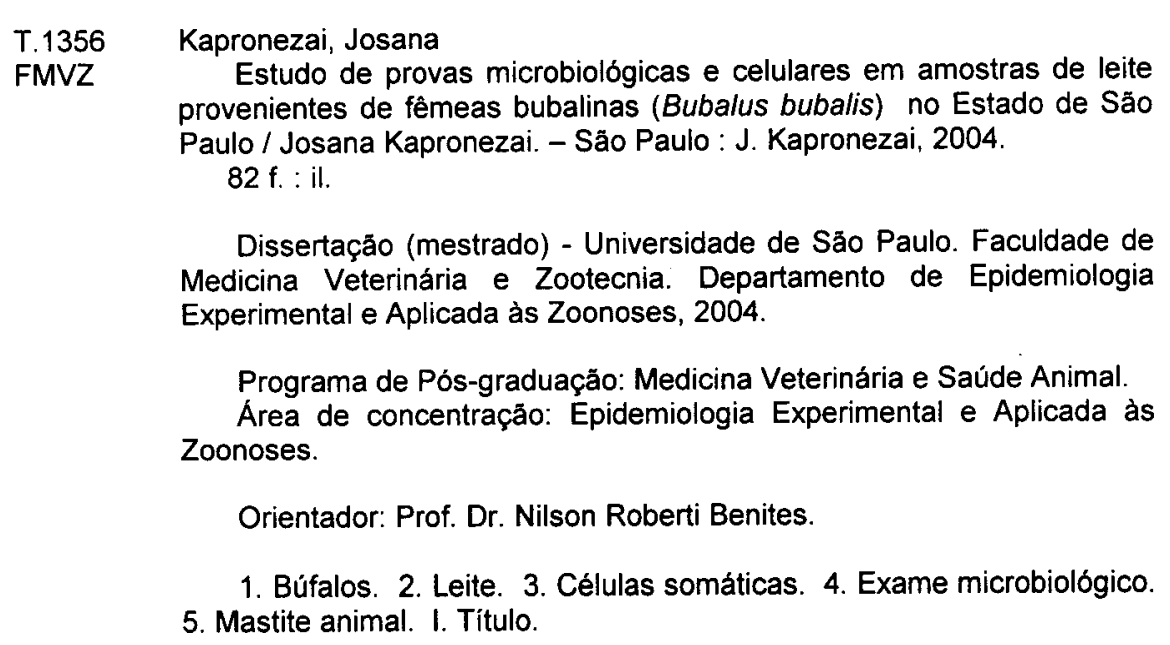

Programa de Pós-graduação: Medicina Veterinária e Saúde Animal.

Área de concentraçăo: Epidemiologia Experimental e Aplicada às Zoonoses.

Orientador: Prof. Dr. Nilson Roberti Benites.

1. Búfalos. 2. Leite. 3. Células somáticas. 4. Exame microbiológico. 5. Mastite animal. I. Título. 


\section{UNIVERSIDADE DE SÃO PAULO \\ Faculdade de Medicina Veterinária e Zootecnia \\ Cidade Universitária "Armando de Salles Oliveira" Comissão Bioética \\ CERTIFICADO}

Certificamos que o Projeto intitulado "Estudo de provas microbiológicas e celulares em amostras de leite provenientes de fêmeas bubalinas (Bubalus bubalis) no Estado de São Paulo", Protocolo

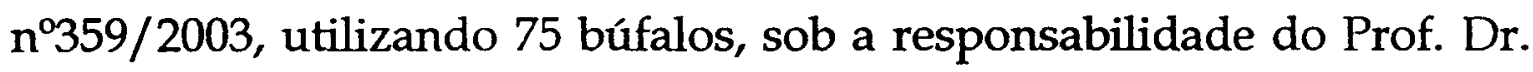
Nilson Roberti Benites, está de acordo com os princípios éticos de experimentação animal da Comissão de Bioética da Faculdade de Medicina Veterinária e Zootecnia da Universidade de São Paulo e foi aprovado em reunião de 29/10/03.

(We certify that the Research "Study of cellular and microbiological probes from buffaloes (Bubalus bubalis) milk samples in São Paulo" protocol number 359/2003, utilizing 75 buffaloes, under the responsibility of Prof. Dr. Nilson Roberti Benites, agree with Ethical Principles in Animal Research adopted by Bioethic Commission of the Faculty of Veterinary Medicine and Zootechny of University of São Paulo and was approved in 10/29/2993, meeting.

São Paulo, 31 de outubro de 2003

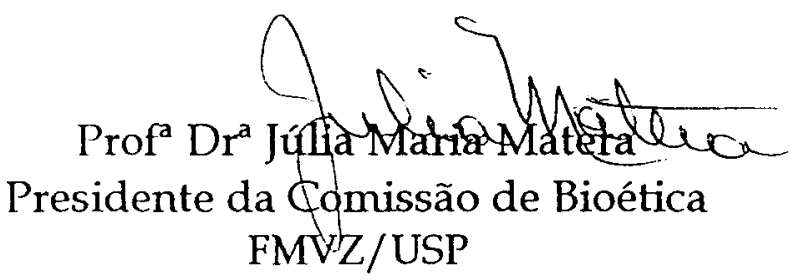




\section{FOLHA DE AVALIAÇÃO}

Nome do autor: KAPRONEZAI, Josana

Título: Estudo de provas microbiológicas e celulares em amostras de leite provenientes de fêmeas bubalinas (Bubalus bubalis) no Estado de São Paulo

artação apresentada ao programa de Pós-graduação em Epidemiologia Experimental e Aplicada às Zoonoses da Faculdade de Medicina Veterinária e Zootecnia da Universidade de São Paulo para a obtenção do título de Mestre em Medicina Veterinária

Data:

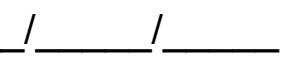

Banca Examinadora

Prof. Dr.

Instituição:

Assinatura:

Julgamento:

Prof. Dr.

Instituição:

Assinatura:

Julgamento:

Prof. Dr.

Instituição:

Assinatura:

Julgamento: 
Aos meu pais, Maria Apparecida e José Kapronezai;

À Klára, presente de Deus, luz que ifumina meus caminhos. 


\section{DEDICATÓRIA}

Dedico este trabalho ao meu pai, José Kapronezai, por seus ensinamentos e sobretudo pelo seu exemplo, referência absoluta de honestidade, sensatez, coragem e amor. Pelo seu apoio incondicional principalmente nos momentos mais dificeis e decisivos da minha vida. Obrigada pai, por ter me proporcionado liberdade de escotha e por ter tornado possivel minha formação nesta profissão, que é meu sonho e que me realiza. Obrigada por ser para mim sempre uma orientação, mostrando-me com sua imensa sabedoria, os caminhos a seguir. Acima de tudo, agradeço a Deus pela certeza de que o senhor edificou em minha filha, os mesmos alicerces fortes do seu caráter, por ter permitido que tudo o que o senhor representa para mim, também o seja para a minha filha.

À minha mãe, Maria Apparecida, pelo seu precioso cuidado com a família e principalmente conosco, seus filhos. Pela personificação do coração e da alma do nosso lar, por sua inteligência, capacidade e responsabilidade. Obrigada por sempre me acother, me reconfortar. Agradeço também por ter me ensinado não apenas os primeiros passos, mas também por ter me mostrado com todo seu amor como o aprendizado e a busca pelo entendimento de todas as coisas que nos rodeiam (ou não), desde as mais simples até as mais complexas, é fascinante. Foi a maneira de fazer com que seus alunos (e filhos) ficassem maravilhados com o mundo novo de descobertas, que dia a dia despertou em mim o interesse e a busca da verdadeira realização que sinto na pesquisa.

À minha filha Klára; por toda a paciência e compreensão. Peço desculpas pelos dias de ausência, por todas as vezes em que não pude estar presente para levá-la à escola, fazer suas tarefas, fazê-la adormecer. Tenha a certeza de que nesses momentos, meu coração sempre esteve com você. Obrigada por mudar minhas prioridades, me ensinar o que é realmente importante nesta vida, me fazer feliz.

À Etelvina Alves Barco, minha avó tão amada, minha segunda mãe; exemplo de amor materno incondicional, que tudo fez pelos seus filhos, sempre com muito amor e felicidade. Espero que me guie sempre, sobretudo para que eu possa, de maneira semelhante, dar à minha filha o que ela sempre me ensinou.

Aos meus avós Stefan Kapronçzai e Berta Prekopp Kapronçzai, que me ensinaram o valor da liberdade, a importância do conhecimento da cultura e dos valores contidos na origem da nossa família. A saudade que traziam nos seus olhos azuis quando nos falavam da beleza das estepes de seu país, da imponência orgulhosa dos Montes Vrais e do remanso calmo e sereno da águas do Rio Danúbio, na coragem da escolha de uma nova vida, na importância da esperança e da crença em um futuro melhor, na união da família. Obrigada por nos mostrarem que honestidade, trabalho, e dedicação são a base para a realização de nossos sonhos. 
À minha irmã Rosana, por sempre me incentivar e acreditar na minha força de trabalho; por ser sempre a pessoa que mais me ajudou com minha filha, principalmente nas horas de desespero e medo de perdê-la, sempre segurando em nossas mãos e nos guiando, levando com segurança de volta. Por ser para a minha filha uma verdadeira mãe: compreensiva, carinhosa, amiga e sempre presente. Farei de tudo para poder retribuir o apoio que sempre nos deu. Obrigada de todo meu coração.

Ao meu irmão Stefan, por todo o apoio que sempre me proporcionou; por representar para a minha filha uma figura protetrora e muito amada. Jamais me esquecerei de tudo o que fez e sei que sempre fará por ela. Obrigada por tratá-la da mesma maneira que trata seus próprios filhos: Stefan e Karoline, a quem amo como se fossem meus... 


\section{AGRADECIMENTTOS}

Ao Prof. Dr. Nilson Roberti Benites, meu orientador, pela confiança e respeito ao meu trabalho; por seu apoio, tão importante e decisivo na continuidade desta pesquisa, $e$ sobretudo pelos ensinamentos de profissão e de vida, que de maneira nobre e sábia estende a todos que o cercam.

Ao Prof. Dr. Marcos Amaku pela elaboração do programa de análise das contagens de células somáticas em esfregaços de leite de búfala.

Ao Prof. Dr. Pietro Sampaio Baruselli pelo auxílio no contato com os proprietários.

À Profa $\operatorname{Dr}^{a}$ Elizabeth O. da Costa pelas informações e pelo interesse neste trabalho.

Aos colegas do Laboratório de Doenças Infecciosas, Priscilla Anne Melville, Simone, Regina e Marcos pelo apoio.

Aos funcionários do Laboratório de Histopatologia do VPT, Luciano Bugalho e Cláudio Arroyo pelo auxílio na coloração e montagem das lâminas.

Aos amigos da pós-graduação: Simone, Miriam, Mônica, Anna Catharina, Leslie, Jennifer, Luís Ivan, pelo companheirismo e pela convivência harmônica e descontraída.

Ao amigo Felício Garino Júnior, por tudo o que me ensinou em Microbiologia, de maneira generosa e com muito boa vontade; pelo seu interesse em nos fazer aprender, de maneira sempre alegre e descontraída. Acima de tudo obrigada pela sua amizade e por sua companhia.

Aos Bubalinocultores, que gentilmente permitiram a entrada nas suas propriedades, confiando seus animais para a colheita das amostras de leite.

Aos funcionários das fazendas, que no cumprimento árduo do seu trabalho diário, demonstrando delicadeza e amor no trato com os animais, me ensinaram a confiança e a aprendizagem recíproca existentes nessa relação.

Às búfalas, pela generosidade e bondade, em permitirem a coleta do leite, esperando pacientemente (com raras exceções) pelo momento de alimentarem seus filhotes.

Às secretárias da pós graduação, por seu auxílio atencioso e eficiente.

Às secretárias do V'PS pela atenção, cuidado e boa vontade com que sempre nos atendem, com alegria e profissionalismo. 
Às Funcionárias da Biblioteca da FMVZ-USP, pela extrema boa vontade, educação e cordialidade no atendimento, sempre pronto e eficiente.

À Faculdade de Medicina Veterinária e Zootecnia da USP, por propiciar a oportunidade de realizar esta pesquisa e pela contribuição na minha formação;

Aos meus tios Maria Guilhermina e Luiz Barco e aos meus primos, pela generosidade em me acolherem em sua casa, me proporcionando além de tudo um lar, onde sinto a segurança e apoio imprescindíveis para agüentar a distância.

À Laura e Lífian, por tudo o que sempre fizeram por mim e por todo apoio e torcida para meu sucesso, minhas primas de sangue, irmãs de coração. Por tudo o que me ensinaram e por me apoiarem nos períodos mais difíceis da minha permanência aqui. Espero um dia poder retribuir à altura. 


\section{RESUMO}

KAPRONEZAI, J. Estudo de provas microbiológicas e celulares em amostras de leite provenientes de fêmeas bubalinas (Bubalus bubalis) no Estado de São Paulo. [Study of microbiological and cellular tests on milk samples from buffalo females (Bubalus bubalis) in State of São Paulo]. 2004. 82 f. Dissertação (Mestrado em Medicina Veterinária) - Faculdade de Medicina Veterinária e Zootecnia, Universidade de São Paulo, 2004.

O presente trabalho teve como objetivo a análise microbiológica das amostras de leite de fêmeas bubalinas, a avaliação da quantidade de UFC/mL dos microrganismos isolados e a contagem de células somáticas $/ \mathrm{mL}$. Os quartos mamários foram submetidos ao teste de tamis e CMT e foram colhidas 262 amostras de leite de fêmeas bubalinas primíparas e pluríparas; para análise microbiológica, quantificação das UFC/mL e contagem de células somáticas $/ \mathrm{mL}$. A contagem das células somáticas foi realizada através da leitura em microscopia ótica dos esfregaços de leite. A leitura foi realizada utilizando-se a totalidade dos campos existentes no esfregaço de $1 \mathrm{~cm}^{2}$. No teste do tamis, $99,6 \%$ das amostras apresentaram resultado negativo. No CMT, observamos resultado negativo em $88,2 \%$ das amostras; traços $(8 \%)$, positivo $1+(1,5 \%)$; positivo $2+(1,15 \%)$; positivo $3+(1,15 \%)$. A análise microbiológica apresentou amostras sem crescimento de microrganismos (75,6\%); isolamento de Staphylococcus spp. (11,8\%); Corynebacterium spp. (7,3\%); Streptococcus spp, $(3,1 \%)$ e crescimento de microrganismos associados (1,2\%). A contagem total de células somáticas das amostras avaliadas apresentou mediana de 2300 células $/ \mathrm{mL}$ de leite; a mediana da contagem de PMN e MN foi, respectivamente, 700 células $/ \mathrm{mL}$ e 1500 células $/ \mathrm{ml}$ de leite, com diferença estatisticamente significante $(P<0,0001)$. As quantidades totais de células somáticas $/ \mathrm{mL}$ e as quantidades de células polimorfonucleares e 
mononucleares nas amostras negativas ao exame microbiológico foram estatisticamente menores do que nas amostras que apresentaram isolamento de microrganismos. A mediana relativa às quantidade de UFC/mL foi de $550 \mathrm{UFC} / \mathrm{mL}$ para as amostras com isolamento de Corynebacterium spp.; $500 \mathrm{UFC/mL} \mathrm{para} \mathrm{as}$ amostras com isolamento de Staphylococcus spp e 1100 UFC/mL para Streptococcus spp. ,sendo que não houve diferença estatisticamente significativa entre eles. Concluiu-se que a espécie bubalina, apresenta baixos índices de mastite; nas amostras com isolamento de microrganismos, o número de UFC/mL é pequeno.Existe um número de animais que apresenta resultado positivo no exame microbiológico do leite, sem contudo apresentar sinais de processo inflamatório.

Palavras-chave: Búfalos. Leite. Células somáticas. Mastite animal. 


\begin{abstract}
KAPRONEZAI, J. Study of microbiological and cellular tests on milk samples from buffalo females (Bubalus bubalis) in State of São Paulo. [Estudo de provas microbiológicas e celulares em amostras de leite provenientes de fêmeas bubalinas (Bubalus bubalis) no Estado de São Paulo]. 2004. 82 f. Dissertação (Mestrado em Medicina Veterinária) - Faculdade de Medicina Veterinária e Zootecnia, Universidade de São Paulo, 2004.
\end{abstract}

The aim of the present study was the microbiological analysis of milk samples from female buffaloes, the amount evaluation of $\mathrm{CFU} / \mathrm{mL}$ of the isolated microorganisms and the somatic cells counting $/ \mathrm{mL}$. The mammary quarters were submitted to strip cup test and CMT and 262 milk samples were colletected from buffalo cows to microbiological analysis, CFU/mL quantification and somatic cells counting. The somatic cells countings were obtained through optical microscopy reading of the milk smears, where all fields of the $1 \mathrm{~cm}^{2}$ smears area were considered. In the strip cup test, $99,6 \%$ of the samples had negative results. In the CMT, the negative results were observed in $88,2 \%$ of the samples; traces ( $8 \%), 1+$ positive $(1,5 \%), 2+$ positive $(1,15 \%)$ and $3+$ positive $(1,15 \%)$. The microbiological analysis resulted in samples with no microorganism growth (75,6\%); Staphylococcus spp $(11,8 \%)$; Corynebacterium spp (7,3\%) and Streptococcus spp (3,1\%) and associated microorganisms growth $(1,15 \%)$. The total counting of somatic cells in the evaluated milk samples showed median of 2300 cells $/ \mathrm{mL}$; while PMN and MN counting median were 700 cells $/ \mathrm{mL}$ and 1500 cells $/ \mathrm{mL}$ respectivelly, with a significant statisticall difference $(P<0,0001)$. The total somatic cells counting $/ \mathrm{mL}$ and the amount of $P M N$ and $\mathrm{MN}$ cells in the microbiological negative samples were statistically smaller than the findings in the samples that showed microorganism isolation. Concerning the 
amount of $\mathrm{CFU} / \mathrm{mL}$, the median obtained for samples with Corynebacterium spp was 550CFU/mL; $500 \mathrm{CFU} / \mathrm{mL}$ for Staphylococcus spp samples and $1100 \mathrm{CFU} / \mathrm{mL}$ for Streptococcus spp results, with no statiscally significant difference between them. It follows that he buffalo species has a low rate of mastitis; the number of CFU/mL is small in the microbiological positive samples. There are a number of animals that despite presenting milk microbiological exam with positive results, showed no signs of inflamatory process.

Key words: Buffalo.Milk. Somatic Cells. Animal Mastitis. 


\section{LISTAS DE GRÁFICOS}

Gráfico 1 - Resultado do teste de tamis realizado a partir de 262 amostras de leite de glândulas mamárias de fêmeas bubalinas - São Paulo -2004

Gráfico 2 - Resultado do "California Mastitis Test" (CMT) realizado a partir de 262 amostras de leite de glândulas mamárias de fêmeas bubalinas - São Paulo - 2004

Gráfico 3 - Processo inflamatório nas 262 amostras de leite de glândulas mamárias de fêmeas bubalinas - São Paulo - 2004

Gráfico 4 - Porcentagem de mastite clínica, subclínica e ausência de mastite nas amostras de leite de glândulas mamárias de fêmeas bubalinas - São Paulo - 2004

Gráfico 5 - Porcentagem de amostras com isolamento de agente único e de associações nas amostras de leite de glândulas mamárias de fêmeas bubalinas positivas ao exame microbiológico - São Paulo - 2004

Gráfico 6 - Comparação entre a contagem de células polimorfonucleares e mononucleares nas amostras de leite de fêmeas bubalinas negativas com isolamento de Staphylococcus spp., Streptococcus spp. e Corynebacterium spp. - São Paulo 2004 


\section{LISTA DE TABELAS}

Tabela 1 - Constituintes do leite bubalino e bovino.

Tabela 2 - Resultado do "California Mastitis Test" (CMT) realizado a partir de 262 amostras de leite de glândulas mamárias de fêmeas bubalinas - São Paulo - 2004

Tabela 3 - Resultado da análise microbiológica realizada a partir das 262 amostras de leite de glândulas mamárias de fêmeas bubalinas - São Paulo 2004

Tabela 4 - Comparação entre os resultados do "California Mastitis Test" (CMT) e da análise microbiológica realizados a partir de 262 amostras de leite de glândulas mamárias de fêmeas bubalinas - São Paulo - 2004

Tabela 5 - Comparação entre o número de unidades formadoras de colônias por $\mathrm{mL}(\mathrm{UFC} / \mathrm{mL}$ ) e o número total de células (CCS), polimorfonucleares (PMN) e mononucleares (MN) entre as amostras microbiologicamente negativas e positivas - São Paulo - 2004

Tabela 6 - Comparação entre as contagens totais de células somáticas por $\mathrm{mL}$ (CCS/mL) e o resultado da análise microbiológica nas amostras de leite de fêmeas bubalinas - São Paulo - 2004

Tabela 7 - Comparação entre a contagem de células polimorfonuclares (células $/ \mathrm{mL}$ ) e o resultado da análise microbiológica nas amostras de leite de glândulas mamárias de fêmeas bubalinas - São Paulo - 2004 
Tabela 8 - Comparação entre a contagem de células mononucleares em amostras de leite de glândulas mamárias de fêmeas bubalinas e o resultado da análise microbiológica - São Paulo - 2004

Tabela 9 - Comparação entre a contagem de células polimorfonucleares e mononucleares nas amostras de leite de fêmeas bubalinas com isolamento de Staphylococcus spp. , Streptococcus spp. e Corynebacterium spp. - São Paulo - 2004.............................................

Tabela 10 - Comparação entre o número de unidades formadoras de colônia por $\mathrm{mL}$ (UFC/ml) nas amostras de leite de fêmeas bubalinas com isolamento de Staphylococcus spp., Streptococcus spp. e Corynebacterium spp. - São Paulo - 2004

Tabela 11 - Comparação entre número de unidades formadoras de colônias por mililitro(UFC/ml) e contagem total de células somáticas por mililitro $(\mathrm{CCS} / \mathrm{ml})$ nas amostras de leite de fêmeas bubalinas segundo o resultado da análise microbiológica - São Paulo - 2004. 



\section{LISTA DE ABREVIATURAS E SIGLAS}

$\mathrm{Ca}$

CCS

$\mathrm{cm}^{2}$

CMT

DNA

FAO

HE

$\lg A$

$\lg \mathrm{G} 1$

K

$\mathrm{Mg}$

$\mathrm{mL}$

$\mathrm{mm}$

$\mathrm{Mn}$

NAPGAMA

$\mathrm{Na}$

$\mathrm{N}^{\circ}$

PMN

$\mathrm{PH}$

SCN-

UFC

r cálcio

contagem de células somáticas

centímetros quadrados

California Mastitis Test

ácido desoxirribonucléico

Food and Agriculture Organization of the United Nations

coloração de hematoxilina e eosina

imunoglobulina A

imunoglobulina G

potássio

magnésio

mililitro

milímetro

manganês

Núcleo de Apoio à Pesquisa em Glândula Mamária e

Produção Leiteira

sódio

número

células polimorfonucleares

potencial hidrogeniônico

íon tiocinato

unidades formadoras de colônias

coeficiente de Spearman 


\section{LISTA DE SÍMBOLOS}

\begin{tabular}{ll}
$\mathrm{m}$ & metro \\
$\mathrm{Kg}$ & igual \\
$\%$ & quilograma \\
$\mathrm{g}$ & porcentagem \\
$/$ & grama \\
$\mathrm{Kcal}$ & divisão \\
$\mathrm{dL}$ & quilocaloria \\
$\mathrm{mg}$ & decilitro \\
- & miligrama \\
+ & negativo \\
\hline $\mathrm{LL}$ & positivo \\
$\mathrm{N}^{\circ}$ & número \\
${ }^{\circ} \mathrm{C}$ & microlitro \\
\hline & maior que \\
\hline & menor que \\
\hline &
\end{tabular}




\section{SUMÁRIO}

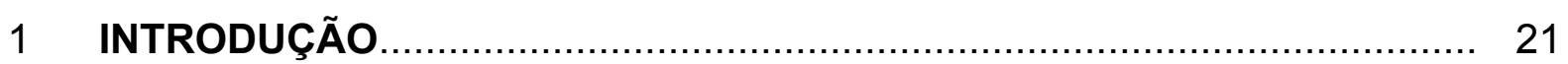

1.1 Aspectos gerais de imunologia...................................................... 26

1.2 Mecanismos de defesa da glândula mamária............................................. 27

2 OBJETIVOS

3 MATERIAIS E MÉTODOS ................................................................... 36

3.1 Animais utilizados no experimento....................................................... 37

3.2 Exame da glândula mamária e do leite.................................................. 38

3.3 Procedimentos de colheita..................................................................... 38

3.4 Avaliação microbiológica e contagem de unidades formadoras de colônias dos microrganismos isolados das amostras de leite de búfalas................... 39

3.5 Contagem de células somáticas em amostras de leite de búfalas............... 40

3.6 Análise estatística....................................................................... 41

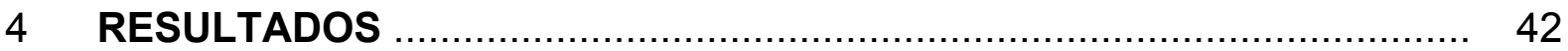

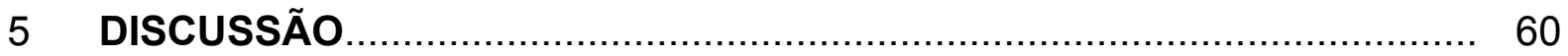

6 CONCLUSÕES

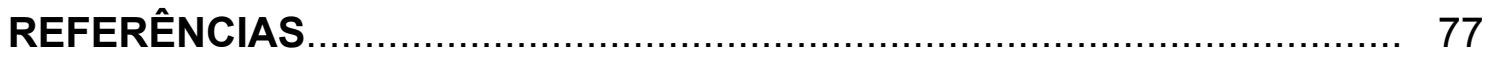



INTRODUÇÃO 


\section{INTRODUÇÃO}

O rebanho bubalino mundial é da ordem de 167,126 milhões de cabeças. 0 Brasil possui o décimo primeiro maior rebanho, com 1,2 milhões de cabeças (FAO, 2003).

Segundo dados relativos ao ano de 2001, o Estado de São Paulo possui o quinto maior rebanho bubalino do país, com 58,9 mil cabeças. O Pará possui um efetivo de 469,2 mil bubalinos, seguido pelos estados do Amapá, Rio Grande do Sul e Maranhão (IBGE, 2003).

No ano de 2002, a produção mundial de leite de búfalo foi de $75,468,126 \mathrm{Mt}$, sendo a Índia o maior produtor com 46.750,000 Mt (FAO, 2003).Considerando-se a produção em anos anteriores, observamos que há um constante aumento na produção de leite de búfalas; sendo que em 1998 a produção mundial foi de $66.897,571 \mathrm{Mt}$.

Os búfalos são agrupados no grupo dos bovinos, uma sub-família da família Bovidae. Há dois grupos principais de búfalos domésticos, o gênero Bubalus, espécie Bubalus bubalis, incluindo o búfalo de rio ou leiteiro com $2 n=50$ cromossomos e o do pântano ou Carabao, com $2 n=48$ cromossomos. Em revisão recente acerca da posição dos búfalos na escala zoológica, propôs-se que o búfalo doméstico fosse classificado dentro de uma sub-família própria a ser chamada de Bubalinae, com duas sub-espécies Bubalus bubalis limneticus (significando lago ou pântano) ou Carabao e Bubalus bubalis fluviatilis (significando rio) ou Murrah, Mediterrâneo, Jafarabadi (VALE, 1994). 
Na América Latina existem os búfalos de rio e do pântano; os animais foram inicialmente importados da Índia, Egito, Itália, Romênia e Filipinas e posteriormente da Bulgária e Itália. O Brasil foi o primeiro país da América Latina a importar búfalos, seguido pela Argentina, Trinidade, Venezuela e Cuba (VALE,1994).

O Búfalo foi introduzido no Brasil entre 1890 e 1895; a história conta que animais Carabao vindos da Guiana Francesa naufragaram na costa sul da ilha do Marajó, localizada na bacia amazônica. Alguns anos mais tarde, animais da raça Mediterrânea foram importados da Itália, e a seguir animais da raça Murrah e Jafarabadi foram trazidos de países asiáticos (BARUSELLI, 1995).

Metade da população de búfalos do Brasil está localizada na região norte do país, em um clima de umidade excessiva e altas temperaturas, onde ocorrem alagamentos e inundações periódicas, com os animais integrando-se naturalmente ao ecossistema da região Amazônica sem causar danos ao patrimônio ambiental, diferentemente do que ocorreria na criação de bovinos. O restante dos animais distribuem-se nas demais áreas do país, integrando-se à produção agropastoril e industrial pré-existente. Nos estados de São Paulo e Paraná destaca-se a produção leiteira destinada à caseificação; a muzzarella assume importância notória no mercado em expansão, principalmente nas grandes cidades do país (BARUSELLI, 1995).

Segundo dados fornecidos pela Associação Brasileira de Criadores de Búfalos, no período de 1985 a 1995 houve um aumento da produção bubalina de $12 \%$ ao ano, o que demonstrava a possibilidade de um grande desenvolvimento da atividade no país (BARUSELLI, 1995).

No Brasil são criados animais das raças Mediterrânea originários da Itália, e Murrah e Jafarabadi, originários da Índia, sendo essas raças pertencentes ao tipo 
"River" (2n=50 cromossomos) e da raça Carabao provenientes do sudeste asiático, pertencente ao tipo "Swamp" (2n=48 cromossomos) (BARUSELLI, 1995).

De acordo com dados fornecidos pela Associação Italiana de Criadores, em 1993, a média de produção por lactação de fêmeas bubalinas da raça mediterrâneo foi de $1912 \mathrm{Kg}$ com $8,1 \%$ de gordura e 4,54\% de proteína e a curva de lactação demonstrou um pico de produção aos 35-50 dias pós-parto. A composição química do leite variou conforme o estágio de lactação; a gordura variou de $7,5 \%$ a $12-14 \%$ e a proteína de $4,0 \%$ a $5,6 \%$, respectivamente no início e final de lactação. A porção protéica do leite de búfala é constituída de $77-79 \%$ de caseína e $23-21 \%$ de soroproteínas. A caseína está presente principalmente sob a forma micelar, na qual a fração b representa $35 \%$ da caseína total. A porção lipídica é formada por glicerídeos (95\% triglicerídeos), ácidos graxos livres, colesterol e fosfolipídeos. A concentração total de colesterol/100g de gordura do leite é menor no leite bubalino que no bovino, ao passo que a fração de colesterol esterificado é maior no leite bubalino. O leite bubalino possui conteúdo mineral maior de $\mathrm{Ca}$ e $\mathrm{Mg}$ e menor de $\mathrm{Na}$, Cl e K quando comparado ao leite bovino (DE FRANCISCIS; DI PALO, 1994).

O búfalo é mais eficiente do que os bovinos em converter forragem grosseira em leite. Os bovinos necessitam de $15.000 \mathrm{Kcal}$ para produzir $1 \mathrm{Kg}$ de leite, enquanto os búfalos requerem 10.000 Kcal para produzir a mesma quantidade, com o dobro de gordura produzido pelos bovinos (VALE,1994).

Tabela 1- Constituintes do leite bubalino e bovino

\begin{tabular}{|c|c|c|c|c|}
\hline Espécie & Gordura & \% Proteína & Lactose & Sólidos Totais \\
\hline Bubalina & 7,64 & 4,36 & 4,83 & 17,96 \\
\hline Bovina & 3,90 & 3,47 & 4,75 & 12,83 \\
\hline
\end{tabular}

Fonte: Vale, 1994. 
Nas propriedades onde as necessidades alimentares dos animais são satisfeitas, o aumento da produção leiteira das fêmeas bubalinas não é significativamente relacionada aos níveis de lipídeos e proteínas do leite, como acontece nas fêmeas bovinas com alta produção (DE FRANCISCIS; DI PALO, 1994).

No Brasil, produções médias de leite de 1.100 a $1.200 \mathrm{Kg}$ com 8,5 a $10 \%$ de gordura são facilmente encontradas entre os rebanhos leiteiros da bacia amazônica. No Estado de São Paulo há uma tendência na utilização do leite de búfala para a fabricação de queijo, principalmente dos tipos mozzarella e ricota; para produzir $1 \mathrm{Kg}$ de queijo, são necessários 8-10 Kg de leite bovino comparados a somente $5 \mathrm{Kg}$ de leite bubalino (VALE, 1994).

O leite de búfalas possui uma atividade antibacteriana maior que o leite bovino, uma vez que contém níveis mais elevados de lactoferrina (DE FRANCISCIS; DI PALO, 1994).

A microbiota do leite de búfalas é muito rica em algumas cepas de lactobacillus que estão presentes em concentrações maiores do que aquelas encontradas no leite bovino. Essas cepas são importantes pois fornecem um sabor e aroma particulares ao queijo, além de ,provavelmente, também serem responsáveis pela acidificação do coágulo durante o processamento do leite (DE FRANCISCIS; DI PALO, 1994). 
1.1 Aspectos gerais de imunologia

As defesas do corpo são constituídas por um complexo sistema de mecanismos sobrepostos e interligados com a finalidade de destruir ou controlar grande parte dos invasores. O primeiro e mais óbvio mecanismo de defesa é representado pelas barreiras físicas à invasão. $\mathrm{O}$ segundo consiste em mecanismos químicos e celulares de defesa sendo conhecido como sistema imunoinato.Um aspecto importante da imunidade inata é a habilidade do corpo de focalizar esses mecanismos de defesa nos sítios de invasão; essa focalização da resposta de defesa é chamada de inflamação. Na inflamação, trocas locais nos tecidos são produzidas pela invasão microbiana ou como resultado de dano tecidual pelo aumento de fluxo sanguíneo e acúmulo local de células que podem atacar e destruir invasores. Essas células chamadas de neutrófilos e monócitos podem comumente destruir a maioria dos invasores e impedir que se espalhem a áreas não infectadas do corpo. O corpo também utiliza enzimas que são produzidas pela presença de invasores para causar destruição microbiana. Essas enzimas constituem o sistema de complemento. $\mathrm{O}$ corpo do animal possui ainda mecanismos especiais para responder a lipopolissacarídeos bacterianos; possuem moléculas antimicrobianas naturais, como lisozimas, enzimas que digerem carboidratos, e muitas proteínas ligadoras a carboidratos. Finalmente, Alguns carboidratos microbianos podem desencadear uma reação específica de defesa chamada de via do complemento alternativa (TIZARD, 2002).

A inflamação e outros componentes do sistema imunoinato contribuem significativamente para a defesa do corpo, contudo é necessário um sistema de 
defesa que seja capaz parar e destruir invasores e aprender do processo, respondendo mais rápida e efetivamente. O tipo de resposta adaptativa é a função do sistema imunoadquirido, um sistema complexo e sofisticado que fornece a defesa máxima do corpo. Esse sistema é dividido em resposta imuno-humoral, onde proteínas denominadas anticorpos, encontradas nos fluidos corpóreos ou humores, destroem os invasores extracelulares ou exógenos; e resposta imunomediada por células, onde células citotóxicas especializadas destroem os invasores intracelulares ou endógenos que causam anormalidades nas células (TIZARD, 2002).

1.2 Mecanismos de defesa da glândula mamária

A defesa da glândula mamária bovina é mediada por uma variedade de mecanismos específicos e não-específicos que atuam sozinhos ou em conjunto para proteger o úbere de infecções. Com poucas exceções, os microrganismos geralmente penetram na glândula mamária através do canal do teto; as propriedades inerentes a ele, que atuam no sentido de impedir a entrada desses microrganismos, constituem a vanguarda de defesa do úbere. Os microrganismos que conseguem ultrapassar a barreira do teto são confrontados por sistemas humorais e celulares de defesa. A falha dos sistemas de defesa pré-existentes da glândula mamária normal em eliminar a infecção nos seus estágios iniciais é caracterizada por uma resposta inflamatória com conseqüente influxo de proteínas séricas e células inflamatórias. Na fase aguda, as células polimorfonucleares migram dos capilares para o sistema de dutos lácteos.Se a infecção não é debelada pela 
atividade fagocítica dessas células, inicia-se o processo crônico de infecção (CRAVEN; WILLIAMS, 1985).

Os mecanismos de defesa da glândula mamária podem ser classificados como sistemas inflamatório- independentes ou dependentes. O primeiro compreende os mecanismos intrínsecos da glândula mamária, os quais, com exceção de um pequeno número de células "residentes", são não fagocíticos: defesas do ducto do teto; defesas humorais não específicas de secreções mamárias; atividade linfocítica e imunoglobulinas na glândula mamária. O segundo compreende a resposta polimorfonuclear e os eventos a ela associados: células fagocíticas na glândula mamária; resposta inflamatória e recrutamento de células PMN; opsonização e fagocitose; atividade microbicida dos fagócitos (CRAVEN; WILLIAMS, 1985).

A glândula mamária utiliza vários mecanismos de defesa diferentes. Em um animal não lactente, um tampão de ceratina bloqueia o orifício da teta e assim expulsa as bactérias. Em um animal lactente a ação da lavagem do leite ajuda a evitar a invasão de alguns patógenos potenciais, enquanto o próprio leite contém muitas substâncias antibacterianas, como complemento, lisozima, latoferrina e lactoperoxidase (TIZARD, 2002).

A lactoferrina compete com as bactérias pelo ferro, tornando-o indisponível e assim impedindo seu crescimento e potencializa a explosão respiratória neutrofílica (TIZARD, 2002). Bathia e Valsa (1994), estudando os níveis de lactoferrina no leite de bubalinos e bovinos de raça indiana, encontraram resultados que demonstram claramente que o leite bubalino é mais rico em lactoferrina do que o leite bovino.

O leite também possui altas concentrações de lactoperoxidase e de íons tiocinato $\left(\mathrm{SCN}^{-}\right)$. Na presença de peróxido de hidrogênio exógeno, a lactoperoxidase pode oxidar o $\mathrm{SCN}^{-}$em produtos bacteriostáticos, tais como o $\mathrm{OSCN}^{-}$. O peróxido 
de hidrogênio pode ser produzido por bactérias, tais como os estreptococos, ou pela oxidação do ácido ascórbico. Algumas cepas de estreptococos são resistentes a esse trajeto bacteriostático, já que possuem uma enzima que reduz o $\mathrm{SCN}^{-}$. O leite de búfalo possui uma atividade da lactoperoxidase $23 \%$ maior do que o leite bovino (KUMAR; BARTHIA, 1994).

As células fagocíticas liberadas no interior da glândula mamária em resposta a uma irritação também contribuem para uma resistência antimicrobiana, não somente pelos seus esforços fagocíticos, como também por proporcionar lactoferrina adicional, peróxido de hidrogênio e peroxidases lisossomais. Pode-se ativar a via clássica do complemento através da conjugação da lactoferrina bovina com o Streptococcus agalactiae não capsulado. A lactoferrina é aparentemente capaz de substituir os anticorpos e o C1q ativado (TIZARD, 2002).

A ação de lavagem do leite ajuda a impedir uma invasão por parte de alguns patógenos potenciais, e o próprio leite contém inibidores bacterianos (lacteninas) e células fagocíticas. Além disso, o leite contém IgA, componente secretor e lgG1. A IgA e o componente secretor se associam intimamente com os glóbulos de gordura do leite. Nos animais de estômago simples, a $\lg A$ predomina, enquanto, nos ruminantes, é a lgG1 a predominante. A lgA é localmente sintetizada no tecido mamário, embora muitas das células produtoras de $\lg A$ na glândula derivem de precursoras originárias do trato intestinal. Essas células constituem uma fonte de anticorpos contra patógenos intestinais. A IgG1, contrariamente, é seletivamente transferida por transporte ativo a partir do soro (TIZARD, 2002).

Se o antígeno for infundido em uma glândula mamária de lactante, ele tende a ser imediatamente lavado e retirado novamente do leite. Se for infundido em uma glândula de não lactante, desenvolve-se uma resposta imune local na qual 
predominam a $\lg \mathrm{A}$ e a $\lg \mathrm{G} 1$. Infelizmente, devido à remoção contínua do leite, a concentração de anticorpos nesse fluido permanece baixa (menor que $100 \mathrm{mg} / \mathrm{dL}$ ) mesmo que, em um período de tempo,a quantidade de imunoglobulinas produzidas pelo úbere possa ser considerável. Na mastite aguda, a resposta inflamatória leva ao influxo de células ativamente fagocíticas, especialmente neutrófilos, e à exudação de proteínas séricas. Como resultado, os níveis de imunoglobulinas no leite na mastite podem se elevar a níveis nos quais elas possam exercer uma influência protetora (800mg/dL) (TIZARD, 2002).

A mastite é uma doença complexa que pode ter diferentes causas, diferentes graus de intensidade e variações na duração e consequências (SCHALM et al., 1971). É um processo inflamatório da glândula mamária que afeta tanto em qualidade quanto em quantidade a produção leiteira e tem como características alterações físicas, químicas e do leite, bem como alterações patológicas do tecido glandular (BLOOD; RADOSTOSIS, 1991).

A glândula mamária é constantemente exposta a uma grande variedade de microrganismos, mas o desenvolvimento ou não de um quadro de mastite infecciosa depende da natureza e da patogenicidade do agente, bem como da susceptibilidade da glândula (DU PREEZ; GIESECKE, 1994).

As búfalas são consideradas menos susceptíveis à mastite do que as vacas (LÁU,1994; SHUKLA; SUPEKAR, 1987), embora os microrganismos envolvidos na infecção sejam semelhantes (NAG, 1995).

No Brasil, Vianni et al. (1990) afirmaram que a taxa de prevalência de mastites em búfalas era de $8,81 \%$. Silva e Silva (1994) consideraram as búfalas mais resistentes às infecções mamárias do que os bovinos, além de apresentarem diferenças quantitativas e qualitativas da celularidade do leite. 
Os bubalinos apresentam os tetos relativamente mais pendulosos e longos, portanto mais sujeitos às injúrias do que os dos bovinos; contudo, o ductus papilaris é mais musculoso, com maior quantidade de fibras e vasos sanguíneos nos bubalinos do que nos bovinos, funcionando como uma barreira mais eficiente contra as infecções (LAU, 1994).

As mastites podem ser classificadas de acordo com a intensidade do processo inflamatório em clínica e subclínica. A mastite clínica se caracteriza por modificações visíveis no leite como a presença de pus ou grumos de fibrina e muitas vezes por alterações na glândula mamária como dor, rubor, aumento de volume e de temperatura. A mastite subclínica não apresenta sinais clínicos evidentes, podendo ser detectada por provas indiretas do leite, como por exemplo o "Califórnia Mastitis Test" - CMT, que detecta um aumento da celularidade (BLOOD; RADOSTOSIS, 1991).

A detecção precoce da mastite nos búfalos, assim como nos bovinos, é muito importante pois reduz as perdas na produção de leite e aumenta as chances de recuperação do animal. Com esse propósito, muitos testes indiretos têm sido estudados e são utilizados para detectar alterações no leite relacionadas á permeabilidade capilar, dano tissular, número de células somáticas, ph, viscosidade, teor de cloretos e de catalase (KUMAR; THAKUR, 2001).

Segundo Schalm et al. (1971), a contagem de células somáticas tem sido aceita como uma das ferramentas mais importantes para a determinação da presença e intensidade do processo inflamatório na glândula mamária. A quantidade e o tipos de células presentes no leite variam sob condições fisiológicas e patológicas. 
O Califórnia Mastitis Test baseia-se na reação de um detergente aniônico (alquil lauril sulfonato de sódio) capaz de emulsionar os lipídeos das membranas dos leucócitos presentes no leite, liberando o DNA que leva à formação de um composto gelificado correspondente à quantidade de células presentes; a intensidade da reação está classificada em 5 scores: negativo, traço (suspeito), positivo 1+, 2+, 3+ (BLOOD; RADOSTOSIS, 1991).

Prescott e Breed (1910) desenvolveram um método para a determinação da quantidade de células no leite através de microscopia ótica direta, sendo que as contagens obtidas deveriam ser consideradas estimativas e não contagens absolutas.

Libera (1998) referiu que inicialmente acreditava-se que a população de células do leite era composta apenas por leucócitos, porém, mais tarde foam identificadas as células epiteliais descamativas da glândula mamária, compondo o que Prescott e Breed (1910) denominaram "body cells". Paape et al. (1963) designou com a expressão de "células somáticas", terminologia consagrada e usada até os dias de hoje. Vários autores definiram diferentes valores como parâmetros de normalidade para a contagem de células somáticas do leite, onde a contagem das células de pende da origem da amostra (um quarto mamário, todos ou um "pool" dos animais), da técnica de contagem, da presença de microrganismos.

Segundo Schalm et al. (1971), o grau de precisão depende do que ele chamou de fator de trabalho, que é uma razão entre o fator do microscópio (relacionado á área do campo visual de cada aparelho) e o número de campos a serem contados na amostra e do número de céluas presentes na mesma. 
A presença de microrganismos no leite e nos derivados, muitos dos quais agentes de zoonoses, podem ser vias potenciais de transmissão de doenças (BADINI, 1995; COSTA et al., 1995)

Em um estudo realizado no Estado de São Paulo, em 29,6\% das amostras de leite bubalino foram isolados microrganismos, sendo que em $77 \%$ delas foi isolado Staphylococcus spp. (GUIDO et al., 1994).

Considerando que em nosso país, segundo estimativas do Ministério da Agricultura, $40 \%$ do leite é consumido "in natura" o controle da qualidade do leite assume papel essencial nos procedimentos que visam assegurar a segurança alimentar da população.

A determinação do número de unidades formadoras de colônias de microrganismos isolados por $\mathrm{mL}$ de leite, realizada em cada quarto que apresente infecção intramamária permite a avaliação da quantidade de microrganismos presentes que são capazes de se multiplicarem. Essas informações, associadas às relacionadas ao tipo e intensidade do processo inflamatório, obtidas através da contagem de células somáticas, permitem uma avaliação mais acurada e real do processo infeccioso e inflamatório nos quartos da glândula mamária. 
OBJETIVOS 


\section{OBJETIVOS}

Os objetivos deste trabalho foram:

- Avaliação microbiológica de amostras de leite de búfalas colhidas no Estado de São Paulo;

- Avaliação do número de unidades formadoras de colônias dos microrganismos isolados nas amostras de leite de búfalas;

- Determinação da celularidade de amostras de leite de búfalas;

- Avaliação qualitativa das células somáticas encontradas nas amostras de leite de búfalas;

- Comparação entre a contagem de células somáticas, status microbiológico e número de unidades formadoras de colônia de microrganismos isolados nas amostras de leite de búfalas. 
MATERIAIS E MÉTODOS 


\section{MATERIAIS E MÉTODOS}

Este trabalho foi realizado utilizando-se as instalações do Laboratório de Doenças Infecciosas - Departamento de Medicina Veterinária Preventiva e Saúde Animal - campus de São Paulo e do Núcleo de Apoio à Pesquisa em Glândula Mamária e Produção Leiteira (NAPGAMA) - campus de Pirassununga.

3.1 Animais utilizados no experimento

Foram avaliadas fêmeas bubalinas primíparas e pluríparas, de diferentes raças e graus de sangue, em diferentes estágios de lactação, pertencentes a propriedades de exploração leiteira localizadas no Estado de São Paulo (municípios de Pirassununga, Sorocaba e Sarapuí), não submetidas a tratamento medicamentoso nos 30 dias anteriores à coleta de material. As propriedades que fizeram parte desta pesquisa possuem plantéis homogêneos, criados em sistema extensivo, sendo alimentados basicamente com volumoso a pasto. A ordenha é mecânica, sendo, na maioria das propriedades, realizada uma vez ao dia, no período da manhã. Em todas as propriedades é realizado o apojo dos bezerros antes do início da ordenha. 
3.2 Exame da glândula mamária e do leite

O úbere das búfalas foi avaliado por inspeção e palpação, examinando-se o parênquima, tetos e estruturas internas (ductus papilaris, sinus papilaris e sinus latifer).

Após o exame físico da glândula mamária, a secreção láctea de cada teto foi submetida à prova do Tamis ou strip cup (BLOOD; RADOSTOSIS, 1989), observando-se a cor e consistência da secreção e a presença de massas ou grumos, a fim de detectar a ocorrência de mastite clínica.

A seguir foi realizado o CMT (Califórnia Mastitis Test) (SCHALM; NOORLANDER, 1957), analisando a alteração na viscosidade da mistura de $2 \mathrm{~mL}$ de reagente com $2 \mathrm{~mL}$ de leite, a fim de detectar a ocorrência de mastite sub-clínica.

\subsection{Procedimentos de colheita}

O úbere era higienizado, retirando-se as sujidades depositadas sob a pele da glândula e dos tetos, tendo-se o cuidado de utilizar uma toalha de papel descartável para cada quarto mamário. A seguir era realizada a antisepsia de cada teto, utilizando-se uma solução de álcool iodado a $10 \%$, principalmente no óstio do ductus papilaris . 
Foram colhidos, de cada quarto mamário, aproximadamente $5 \mathrm{~mL}$ de leite em tubos de vidro estéreis (16X160 mm com rolha de borracha $\mathrm{n}^{\circ} 40$ ), para a análise microbiológica e $5 \mathrm{~mL}$ de leite em tubos plásticos tipo Falcon, para a avaliação da celularidade das amostras. As amostras foram transportadas ao laboratório sob condições monitoradas de refrigeração, sendo processadas no menor tempo possível, nunca excedendo um período de 06 horas a partir da colheita.

3.4 Avaliação microbiológica e contagem de unidades formadoras de colônias dos microrganismos isolados das amostras de leite de búfalas.

As amostras de leite foram inicialmente submetidas aos exames microbiológicos, sendo cultivadas em ágar sangue de carneiro $(5 \%)^{1}$ com incubação em aerobiose a $37^{\circ} \mathrm{C}$, com leituras de 24 a 96 horas.

Os microrganismos isolados foram identificados de acordo com Lennete (1985) e classificados segundo Krieg e Holt (1994), Murray et al. (1999).

A partir das amostras de leite em que houve crescimento, foi realizada a contagem de unidades formadoras de colônias por mL (UFC) do microrganismo isolado. As amostras de leite foram diluídas em solução fisiológica $0,85 \%$ estéril; a partir de cada diluição $\left(10^{0}, 10^{-1}, 10^{-2}, 10^{-3}, 10^{-4}\right)$, foi colhida uma alíquota de $0,1 \mathrm{~mL}$ para cultivo (utilizando-se a técnica de spread plate ou espalhamento em placa) em duplicata em ágar sangue de carneiro (no caso de isolamento de bactérias), com incubação a $37^{\circ} \mathrm{C}$ por 48 horas, bem como bem como em duplicata em ágar

\footnotetext{
${ }^{1}$ Blood Agar base - Oxoid - Hampshire - UK.
} 
Sabouraud-dextrose (no caso de isolamento de fungos micelianos, leveduras ou algas), com incubação a temperatura ambiente por um período de sete dias, visando à determinação do número de UFC/mL.

3.5 Contagem de células somáticas em amostras de leite de búfalas

A contagem de células somáticas das amostras de leite de búfalas foi realizada segundo o método de Prescott e Breed (1910), modificado com a coloração de hematoxilina-eosina (HE) (BENITES et al., 2001). Segundo a técnica, um volume de $10 \mu \mathrm{l}$ (em duplicata) foi distribuído em uma área de $1 \mathrm{~cm}^{2}$ em lâmina de vidro previamente limpa e desengordurada. Após a secagem, o esfregaço foi fixado em metanol por 15minutos; as lâminas foram secas e então coradas com a coloração de HE. As contagens de células somáticas foram realizadas usando-se microscopia ótica (objetiva de imersão 100x e ocular 10x). Devido à baixa contagem das células somáticas optou-se por realizá-la na área total dos esfregaços de leite; estes continham aproximadamente 50 linhas com largura correspondente ao diâmetro do campo do microscópio utilizado para esse fim. 
3.6 Análise Estatística

A análise estatística foi realizada utilizando-se o "software" GRAPHPAD INSTAT 1990-1993.

A comparação entre a quantidade total de célula somáticas $/ \mathrm{mL}$ de leite e os resultados da análise microbiológica das amostras foi feita através do teste estatístico não paramétrico de Kruskal-Wallis e do teste de comparações múltiplas de Dunn.

Considerando a quantidade estimada de células polimorfonucleares e mononucleares por $\mathrm{mL}$ de leite e os resultados da análise microbiológica das amostras estudadas, a análise estatística foi realizada através do teste estatístico não paramétrico de Kruskal-Wallis e do teste de comparações múltiplas de Dunn.

Nas amostras em que foram isolados Staphylococcus spp., Streptococcus spp. e Corynebacterium spp., a comparação entre as quantidades de células polimorfonucleares e células mononucleares foi realizada através do teste estatístico de Wilcoxon e a correlação entre as quantidades das células polimorfonucleares e mononucleares das amostras foi determinada através do coeficiente não paramétrico de correlação de Spearman.

A relação entre a quantidade de $U F C / m L$ e a contagem total de células somáticas nas amostras de leite estudadas foi determinada através do teste estatístico de Wilcoxon e do coeficiente de correlação de Spearman.

As proporções entre os resultados da análise microbiológica das amostras foram calculadas pelo teste de Fischer. 
RESULTADOS 


\section{RESULTADOS}

Neste trabalho foram avaliados 262 quartos mamários de fêmeas bubalinas pertencentes a propriedades localizadas no Estado de São Paulo. No teste do tamis, uma $(0,4 \%)$ amostra apresentou resultado +3 e $261(99,6 \%)$ amostras apresentaram resultado negativo (Gráfico 1).

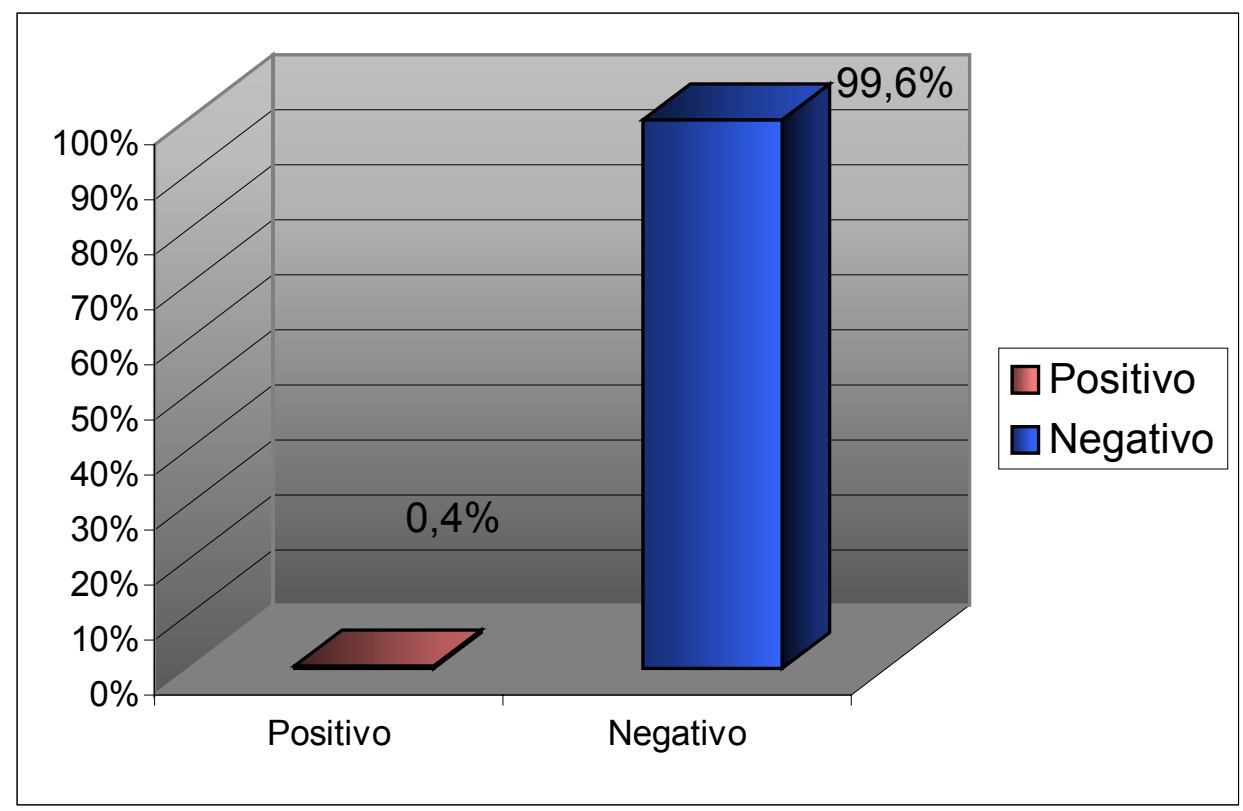

Gráfico 1 - Resultado do teste de tamis realizado a partir de 262 amostras de leite de glândulas mamárias de fêmeas bubalinas - São Paulo - 2004

Considerando-se o CMT, 231 (88,2\%) amostras apresentaram reação negativa ao CMT; $21(8,0 \%)$ amostras apresentaram traços ao CMT; quatro $(1,5 \%)$ amostras apresentaram reação 1+ ao CMT; três $(1,15 \%)$ amostras apresentaram 
reação 2+ ao CMT; três $(1,15 \%)$ amostras apresentaram reação $3+$ ao CMT (Tabela 2) (Gráfico 2).

Tabela 2 - Resultado do "California Mastitis Test" (CMT) realizado a partir de 262 amostras de leite de glândulas mamárias de fêmeas bubalinas - São Paulo - 2004

\begin{tabular}{lcc}
\hline Escore de CMT & $\mathbf{N}^{\mathbf{0}}$ Amostras & $\mathbf{\%}$ \\
\hline Negativo & 231 & 88,20 \\
Traços & 21 & 8,00 \\
$1+$ & 4 & 1,50 \\
$2+$ & 3 & 1,15 \\
$3+$ & 3 & 1,15 \\
\hline TOTAL & 262 & 100,00 \\
\hline
\end{tabular}

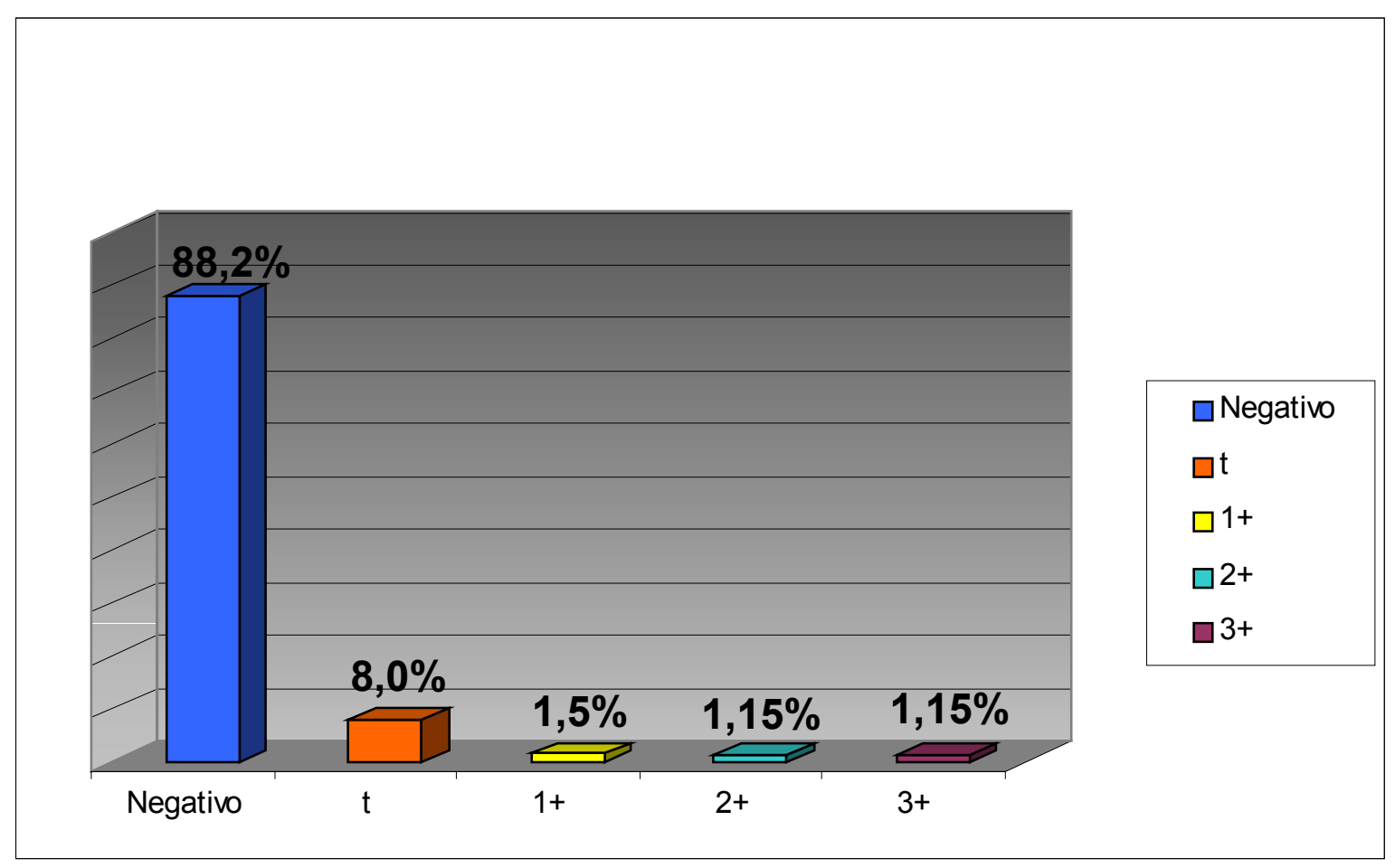

Gráfico 2 - Resultado do "California Mastitis Test" (CMT) realizado a partir de 262 amostras de leite de glândulas mamárias de fêmeas bubalinas - São Paulo - 2004 
Com base nos resultados do CMT, dez (3,8\%) dos quartos mamários avaliados apresentaram processo inflamatório e 252 (96,2\%) não apresentaram processo inflamatório em curso (Gráfico 3).

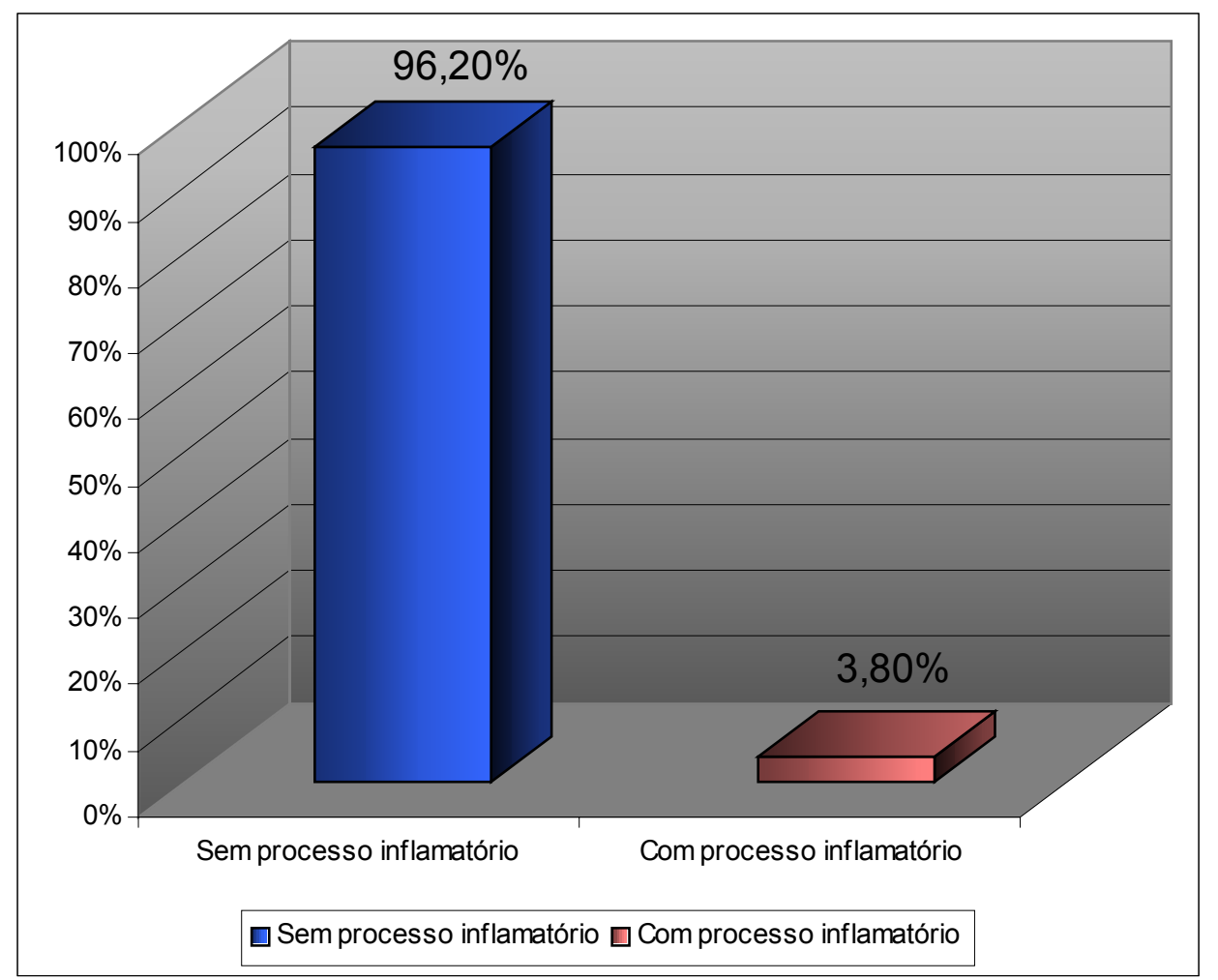

Gráfico 3 - Processo inflamatório nas 262 amostras de leite de glândulas mamárias de fêmeas bubalinas - São Paulo - 2004 
Baseados nos resultados do teste do tamis e do CMT, 0,4\% dos quartos mamários apresentaram mastite clínica; 3,4\% mastite subclínica e 96,2\% foram negativos (Gráfico 4).

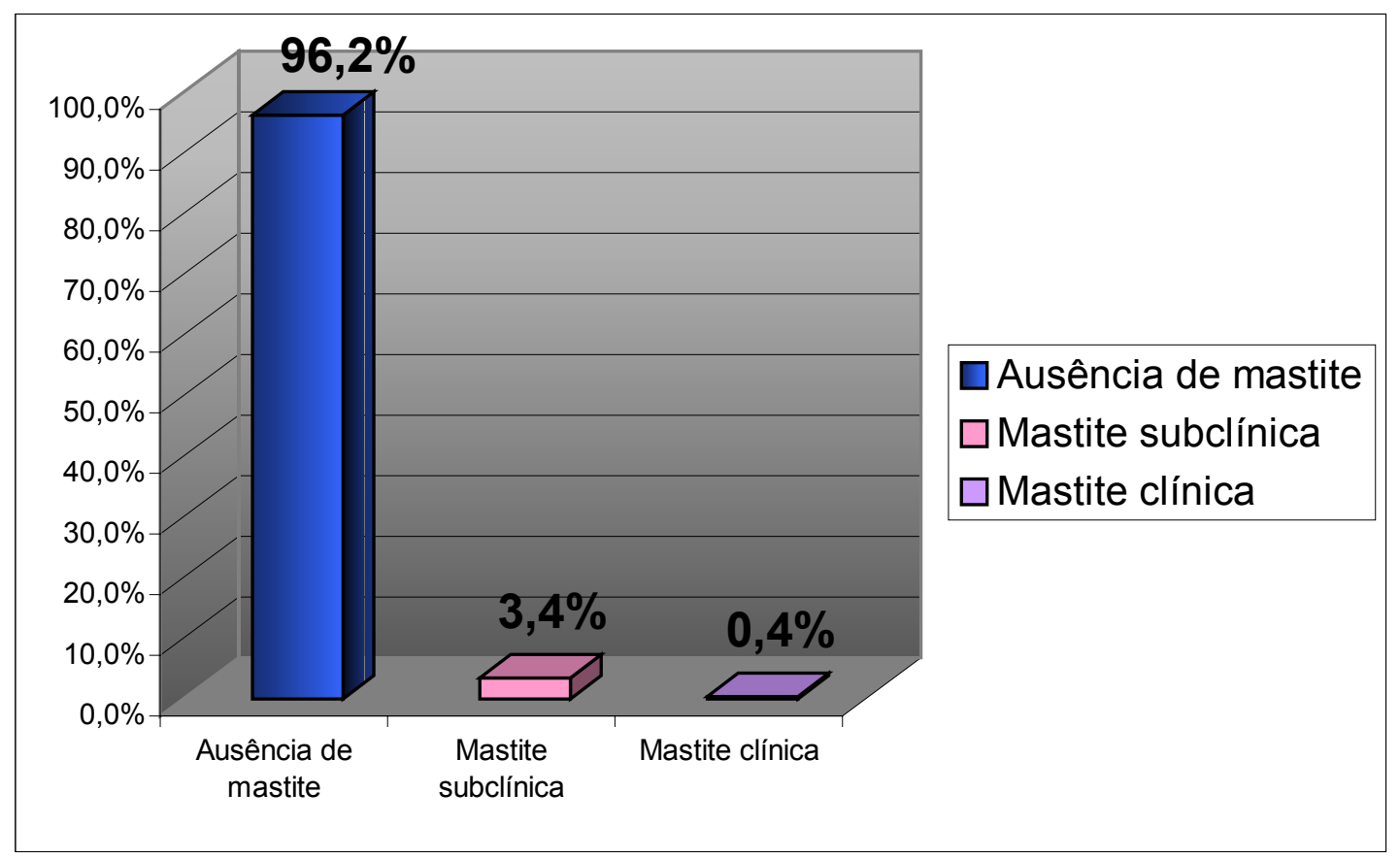

Gráfico 4 - Porcentagem de mastite clínica, subclínica e ausência de mastite nas amostras de leite de glândulas mamárias de fêmeas bubalinas - São Paulo - 2004

Considerando a análise microbiológica das 262 amostras de leite de fêmeas bubalinas, em 198 amostras (75,6\%) não houve crescimento de bactérias aeróbicas, algas e/ou fungos. Nas amostras que apresentaram crescimento de microrganismos, 
foi isolado Staphylococcus spp. em 31 amostras, correspondendo a $11,8 \%$ do total de amostras analisadas; Corynebacterium spp. em 19 amostras (7,25\%); Streptococcus spp. em oito amostras (3,0\%); Streptococcus spp. e Corynebacterium spp. associados em uma amostra (0,4\%); Corynebacterium spp. e Staphylococcus spp. associados em uma amostra (0,4\%); Staphylococcus spp. e Streptococcus spp. em três amostras (1,15\%) e Staphylococcus spp., Streptococcus spp. e Corynebacterium spp. em uma amostra $(0,4 \%)$ (Tabela 3$)$.

Tabela 3 - Resultado da análise microbiológica realizada a partir das 262 amostras de leite de glândulas mamárias de fêmeas bubalinas - São Paulo - 2004

\begin{tabular}{lcc}
\hline \multicolumn{1}{c}{ Análise microbiológica } & $\mathbf{N}^{\mathbf{0}}$ & $\mathbf{\%}$ \\
\hline Ausência de crescimento & $198^{\mathrm{a}}$ & 75,6 \\
Staphylococcus spp. & $31^{\mathrm{b}}$ & 11,8 \\
Corynebacterium spp. & 19 & 7,25 \\
Streptococcus spp. & 08 & 3,0 \\
Staphylococcus spp. e Streptococcus spp. & 03 & 1,15 \\
Staphylococcus spp. e Corynebacterium spp. & 01 & 0,4 \\
Streptococcus spp. e Corynebacterium spp. & 01 & 0,4 \\
Staphylococcus spp. Streptococcus spp e Corynebacterium spp & 01 & 0,4 \\
\hline Total & 262 & 100 \\
\hline
\end{tabular}

$a=$ diferença estatisticamente significante $(P<0,0001)$ quando comparado com as amostras com isolamento de microrganismos.

$b=$ diferença estatisticamente significante $(P<0,0001)$ quando comparados aos outros agentes. 
Das amostras positivas ao exame microbiológico, em $58(97,7 \%)$ foi isolado um único agente e em seis amostras, foram isolados microrganismos associados (Gráfico 5).

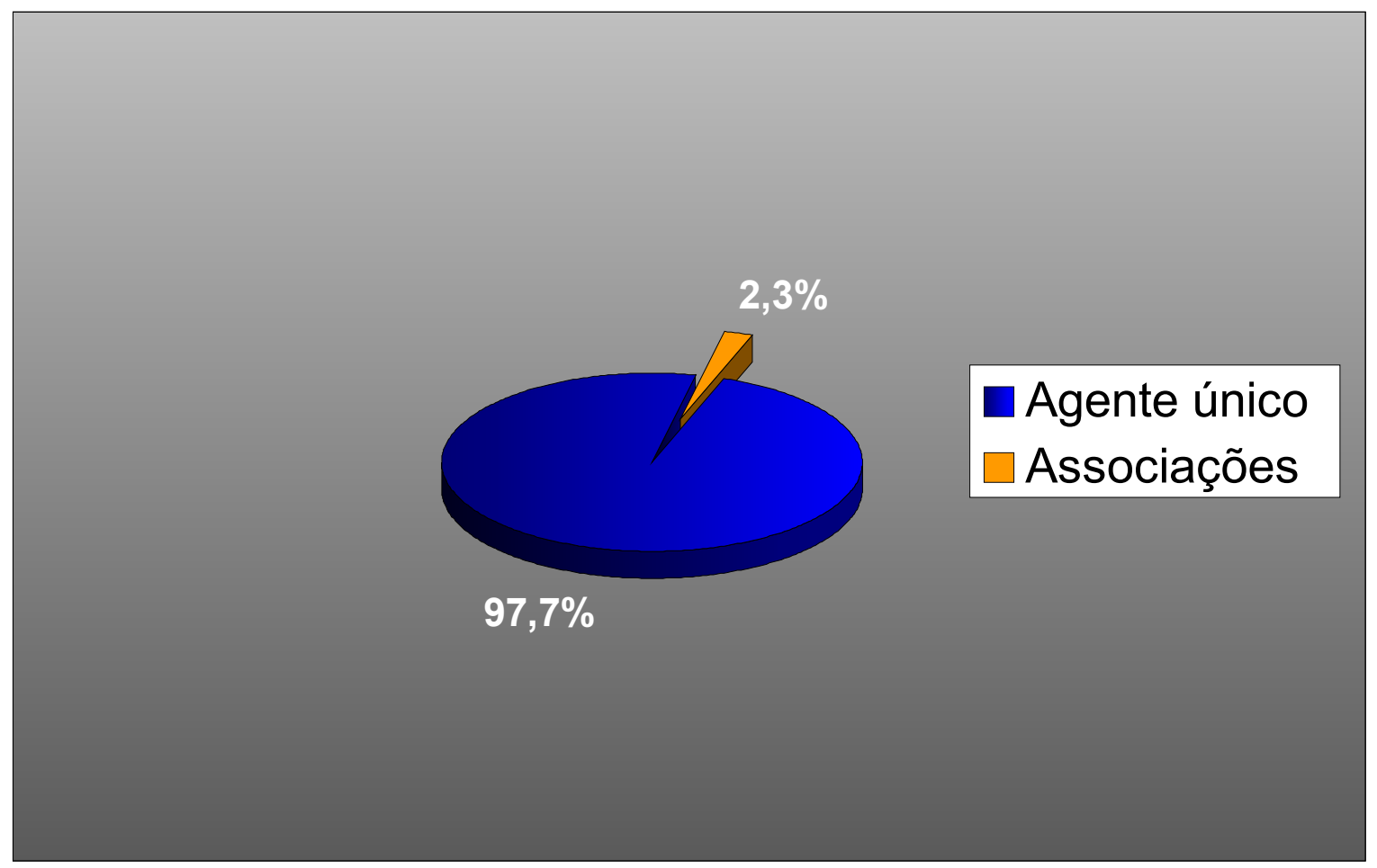

Gráfico 5 - Porcentagem de amostras com isolamento de agente único e de associações nas amostras de leite de glândulas mamárias de fêmeas bubalinas positivas ao exame microbiológico - São Paulo - 2004

O número de amostras negativas ao exame microbiológico é estatisticamente maior do que o de amostras que apresentaram isolamento de microrganismos $(\mathrm{P}<0,0001)$ (Tabela 3). Considerando as amostras positivas ao exame 
microbiológico, a freqüência de isolamento de Corynebacterium spp. e Staphylococcus spp. foi estatisticamente maior $(P<0,0001)$ do que a dos outros agentes observados (Tabela 3).

Considerando os resultados do exame microbiológico e do CMT das amostras de leite de fêmeas bubalinas avaliadas, encontramos nas 231 amostras que apresentaram resultado negativo ao $\mathrm{CMT}$, isolamento de microrganismos em 50 delas. Nas 31 amostras que apresentaram resultados positivos ao CMT, 14 apresentaram crescimento de microrganismos e 17 foram negativas ao exame microbiológico (Tabela 4).

Tabela 4 - Comparação entre os resultados do "California Mastitis Test" (CMT) e da análise microbiológica realizados a partir de 262 amostras de leite de glândulas mamárias de fêmeas bubalinas - São Paulo - 2004

\begin{tabular}{lcc}
\hline & Positivo & Negativo \\
Análise microbiológica & & \\
\hline Positivo & 14 & $50^{\mathrm{a}}$ \\
Negativo & 17 & $181^{\mathrm{b}}$ \\
\hline Total & 31 & 231 \\
\hline
\end{tabular}

$a=$ freqüência estatisticamente maior de quartos negativos no CMT quando comparado com a freqüência de quartos positivos no CMT $(P<0,05)$.

$b=$ freqüência estatisticamente maior de quartos negativos no CMT quando comparado com a freqüência de quartos positivos no CMT $(P<0,05)$. 
A freqüência de quartos negativos no CMT e com isolamento microbiológico foi maior estatisticamente $(P<0,05)$ do que a freqüência de quartos positivos no CMT e com isolamento de microrganismos. A freqüência de quartos negativos no CMT e sem isolamento de microrganismos foi estatisticamente maior $(P<0,05)$ do que a freqüência de quartos positivos no CMT e sem isolamento (Tabela 4).

Nas amostras de leite em que houve crescimento de microrganismos, foram identificadas as seguintes espécies: Staphylococcus spp. (S. hominis, $S$. epidermidis, S. cohnei, S. schleiferi, S. intermedius, S. hyicus), Streptococcus spp. (S. dysgalactiae, S. agalactiae), Corynebacterium spp. (C. bovis, C. xerosis).

A contagem total de células somáticas das 262 amostras avaliadas apresentou mediana de 2300 células/mL de leite (100 - 630900) (Tabela 5).

Tabela 5 - Comparação entre o número de unidades formadoras de colônias por $\mathrm{mL}$ (UFC/mL) e o número total de células (CCS), polimorfonucleares (PMN) e mononucleares (MN) entre as amostras microbiologicamente negativas e positivas - São Paulo - 2004

\begin{tabular}{lcccc}
\hline & $\mathbf{N}^{\mathbf{0}}$ & Mediana & Mínima & Máxima \\
\hline PMN & 262 & $700^{\mathrm{a}}$ & 0 & 603500 \\
MN & 262 & 1500 & 0 & 178000 \\
CCS & 262 & 2300 & 100 & 630900 \\
UFC & 262 & 0 & 0 & 475000 \\
\hline
\end{tabular}

$a=$ diferença estatisticamente significante $(P<0,0001)$ entre $P M N$ e $M N$. 
O número de células polimorfonucleares e mononucleares, nas 262 amostras avaliadas, apresentou mediana de 700 células $/ \mathrm{mL}(0$ - 603500) e 1500 células $/ \mathrm{mL}$ $(0-178000)$, respectivamente (Tabela 5). O número de células mononucleares é estatisticamente maior do que o de células polimorfonucleares $(P<0,0001)$ (Tabela 5). Comparando os tipos celulares encontrados nas amostras, observamos valores maiores de células mononucleares, caracterizando predomínio de processos inflamatórios crônicos nos quartos mamários das fêmeas bubalinas avaliadas neste trabalho.

A quantificação das UFC/mL nas 262 amostras avaliadas obteve mediana 0 $(0-475000)$ (Tabela 5).

A contagem total de células somáticas nas amostras negativas ao exame microbiológico obteve uma mediana de 1900 células/mL de leite (valor mínimo 100 valor máximo 169300). Considerando as amostras nas quais foram isolados microrganismos, a mediana das contagens totais de células somáticas apresentou valor de 8500 células/mL (1000 - 328800) nas amostras onde Staphylococcus spp. foi isolado; 10350 células/mL (1700 - 65800) nas amostras onde Streptococcus spp. foi isolado e 9600 células/mL (700 - 630900) nas amostras onde Corynebacterium spp. foi isolado (Tabela 6). 
Tabela 6 - Comparação entre as contagens totais de células somáticas por $\mathrm{mL}$ (CCS $/ \mathrm{mL})$ e o resultado da análise microbiológica nas amostras de leite de fêmeas bubalinas - São Paulo - 2004

\begin{tabular}{lcccc}
\hline $\begin{array}{c}\text { Resultado Análise } \\
\text { Microbiológica }\end{array}$ & No $^{\mathbf{c}}$ & Mediana & Mínima & Máxima \\
\hline Negativo & 198 & $1900^{\mathrm{a}}$ & 100 & 169300 \\
Staphylococcus spp. & 31 & 8500 & 1000 & 328800 \\
Corynebacterium spp. & 19 & 9600 & 700 & 630900 \\
Streptococcus spp. & 08 & 10350 & 1700 & 65800 \\
\hline
\end{tabular}

$a=$ diferença estatisticamente significante quando comparadas às amostras com isolamento de Staphylococcus spp. $(\mathrm{P}<0,01)$; Streptococcus spp. $(\mathrm{P}<0,01)$ e Corynebacterium spp. $(P<0,001)$.

As quantidades totais de células somáticas $/ \mathrm{mL}$ nas amostras negativas ao exame microbiológico foram estatisticamente menores do que as quantidades totais de células $/ \mathrm{mL}$ das amostras que apresentaram crescimento de microrganismos. As contagens totais de células somáticas das amostras onde não houve crescimento de microrganismos diferiram significativamente das contagens das amostras nas quais foi isolado Staphylococcus spp. $(P<0,001)$; Streptococcus spp. $\quad(P<0,01)$ e Corynebacterium spp. $(\mathrm{P}<0,001)$. Comparando as amostras que apresentaram crescimento de Staphylococcus spp., Streptococcus spp. e Corynebacterium spp. não houve diferença significante estatisticamente nas quantidades totais de células somáticas $/ \mathrm{mL}$ de leite $(P>0,05)$ (Tabela 6$)$.

Nas amostras negativas ao exame microbiológico, o número de células polimorfonucleares apresentou mediana de 600 células $/ \mathrm{mL}$ de leite (valor mínimo 0 valor máximo 61300). Em amostras nas quais foram isolados microrganismos, a mediana das quantidades de células polimorfonucleares foi de 4800 células $/ \mathrm{mL}$ (300 - 603500) para Corynebacterium spp.; 4500 células polimorfonucleares (300 - 
274100) para Staphylococcus spp. e 6850 células polimorfonucleares (700 - 38600) para Streptococcus spp. (Tabela 7).

Tabela 7 - Comparação entre a contagem de células polimorfonucleares (células $/ \mathrm{ml}$ ) e o resultado da análise microbiológica nas amostras de leite de glândulas mamárias de fêmeas bubalinas - São Paulo - 2004

\begin{tabular}{lcccc}
\hline & $\mathbf{N}^{\mathbf{0}}$ & Mediana & Mínima & Máxima \\
\hline Negativo & 198 & $600^{\mathrm{a}}$ & 0 & 61300 \\
Staphylococcus spp. & 31 & 4500 & 300 & 274100 \\
Corynebacterium spp. & 19 & 4800 & 300 & 603500 \\
Streptococcus spp. & 08 & 6850 & 700 & 38600 \\
\hline
\end{tabular}

$\mathrm{a}=$ diferença estatisticamente significante $(\mathrm{P}<0,01)$ quando comparado com Staphylococcus spp., Streptococcus spp. e Corynebacterium spp.

Considerando a quantidade de células polimorfonucleares estimada e o resultado do exame microbiológico nas amostras analisadas, observamos que, naquelas em que não houve crescimento de microrganismos, o número de células polimorfonucleares apresentou valores estatisticamente menores do que nas amostras em que foram isolados Corynebacterium spp. $(P<0,001)$, Staphylococcus spp. $(P<0,001)$ e Streptococcus spp. $(P<0,001)$ (Tabela 7$)$.

O número de células polimorfonucleares nas amostra de leite com isolamento de Staphylococcus spp., Streptococcus spp. e Corynebacterium spp. não apresentou valores estatisticamente significantes $(P>0,05)$ (Tabela 7).

As amostras negativas ao exame microbiológico apresentaram mediana de 1150 células mononucleares/mL de leite (valor mínimo 0 - valor máximo 108000); as 
amostras com isolamento de Corynebacterium spp., 4800 células mononucleares/mL (400 - 27400); as amostras com isolamento de Staphylococcus spp. 4600 células mononucleares/mL (600 - 178000) e as amostras com isolamento de Streptococcus spp., 3700 células mononucleares/mL (1000 - 29500) (Tabela 8).

Tabela 8 - Comparação entre a contagem de células mononucleares em amostras de leite de glândulas mamárias de fêmeas bubalinas e o resultado da análise microbiológica - São Paulo - 2004

\begin{tabular}{lcccc}
\hline & N $^{\mathbf{0}}$ & Mediana & Mínima & Máxima \\
\hline Negativo & 198 & $1150^{\text {a }}$ & 0 & 108000 \\
Staphylococcus spp. & 31 & 4600 & 600 & 178000 \\
Corynebacterium spp. & 08 & 4800 & 400 & 27400 \\
Streptococcus spp. & 19 & 3700 & 1000 & 29500 \\
\hline
\end{tabular}

$a=$ diferença estatisticamente significante quando comparada com Staphylococcus spp. $(P<0,001)$, Corynebacterium spp. $(\mathrm{P}<0,001)$ e Streptococcus spp. $(\mathrm{P}<0,01)$.

Nas amostras negativas ao exame microbiológico, a quantidade de células mononucleares estimada foi estatisticamente menor do que nas amostras com isolamento de Corynebacterium spp. e Staphylococcus spp. $(P<0,001)$ e na amostras com isolamento de Streptococcus spp. $(\mathrm{P}<0,01)$ (Tabela 8).

Não houve diferença estatisticamente significante quando foram comparadas as quantidades de células mononucleares obtidas nas amostras em que foram isolados Corynebacterium spp., Staphylococcus spp. e Streptococcus spp. $(\mathrm{P}>0,05)$ (Tabela 8). 
Nas 262 amostras de leite estudadas, foi determinada diferença estatisticamente significante entre as quantidades de células polimorfonucleares e mononucleares $(P<0,0001)$. O coeficiente de correlação de Spearman relativo às quantidades de células polimorfonucleares e mononucleares das amostras estudadas foi de 0,7660 ( $P<0,0001)$, demonstrando a existência de correlação extremamente significante entre os parâmetros avaliados (Tabela 9) (Gráfico 6).

Tabela 9 - Comparação entre a contagem de células polimorfonucleares e mononucleares nas amostras de leite de fêmeas bubalinas com isolamento de Staphylococcus spp. , Streptococcus spp. e Corynebacterium spp. - São Paulo - 2004

\begin{tabular}{lcc}
\hline & Polimorfonucleares & Mononucleares \\
\hline Staphylococcus spp. & 4500 & $4600^{\mathrm{a}}$ \\
Corynebacterium spp. & 4800 & $4800^{\mathrm{b}}$ \\
Streptococcus spp. & 6850 & $3700^{\mathrm{c}}$ \\
\hline
\end{tabular}

$a=$ coeficiente de correlação de Spearman $r=0,8930$ para $\mathrm{P}<0,0001$.

$b=$ coeficiente de correlação de Spearman $r=0,9236$ para $P<0,0001$.

$c=$ coeficiente de correlação de Spearman $r=0,8333$ para $\mathrm{P}=0,0077$. 


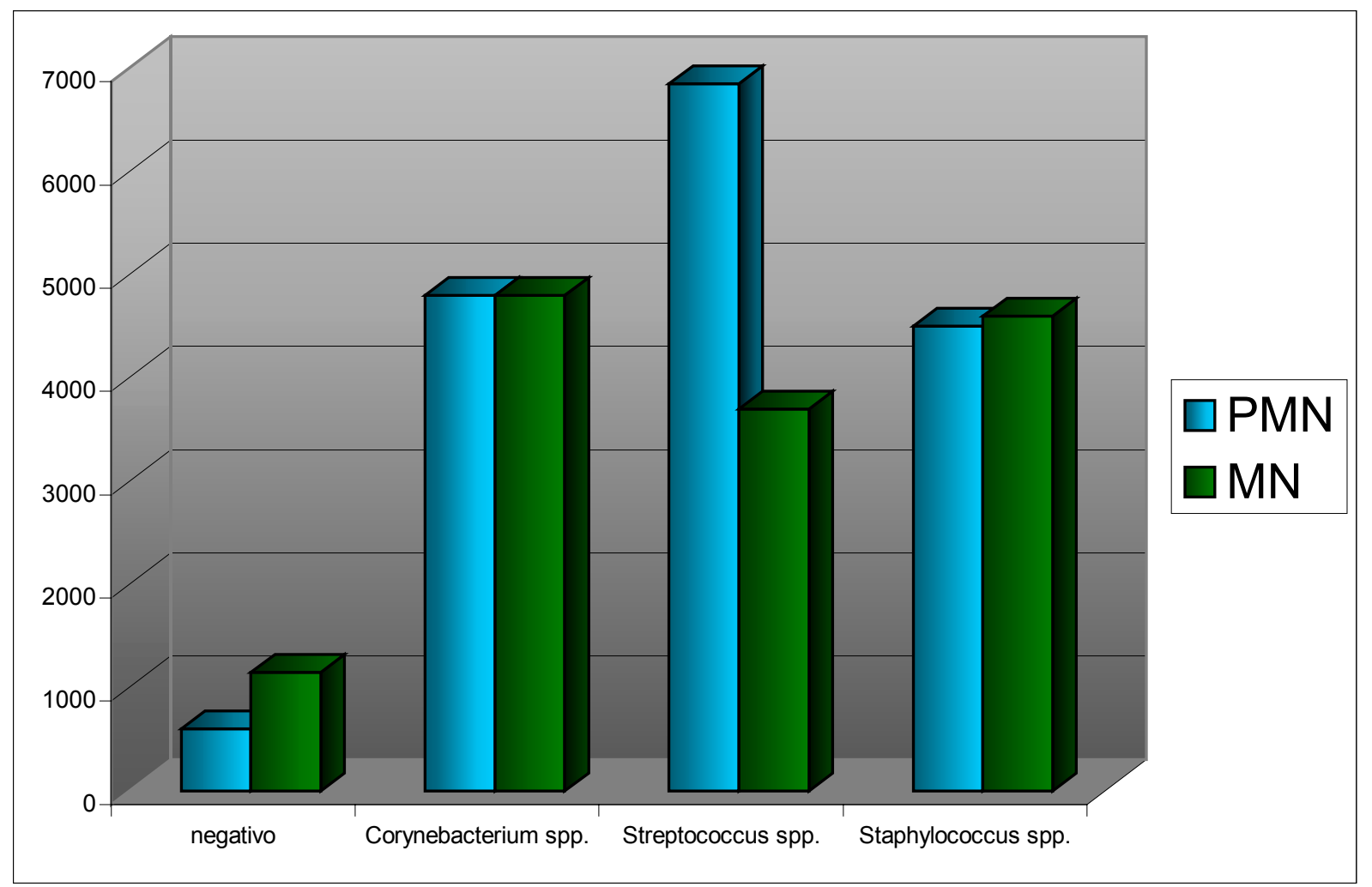

Gráfico 6 - Comparação entre a contagem de células polimorfonucleares e mononucleares nas amostras de leite de fêmeas bubalinas negativas com isolamento de Staphylococcus spp., Streptococcus spp. e Corynebacterium spp. - São Paulo - 2004

Nas amostras de leite em que Staphylococcus spp. foi isolado, não foi determinada diferença estatisticamente significante entre as quantidades de células polimorfonucleares e células mononucleares. O coeficiente de correlação de Spearman relativo às quantidades de células polimorfonucleares e mononucleares 
nas amostras de leite com isolamento de Staphylococcus spp foi de 0,8930 e $P<0,0001$, demonstrando a existência de correlação extremamente significante entre os parâmetros estudados (Tabela 9) (Gráfico 6).

Nas amostras de leite em que Streptococcus spp. foi isolado, não foi determinada diferença estatisticamente significante entre as quantidades de células polimorfonucleares e células mononucleares. O coeficiente de correlação de Spearman relativo às quantidades de células polimorfonucleares e mononucleares nas amostras de leite com isolamento de Streptococcus spp foi de 0,8333 e $P=0,0077$, demonstrando a existência de correlação muito significativa entre os parâmetros estudados (Tabela 9) (Gráfico 6).

Nas amostras de leite em que Corynebacterium spp. foi isolado, não foi determinada diferença estatisticamente significante entre as quantidades de células polimorfonucleares e células mononucleares.O coeficiente de correlação de Spearman relativo às quantidades de células polimorfonucleares e mononucleares nas amostras de leite com isolamento de Corynebacterium spp. foi de 0,9236 e $P<0,0001$, demonstrando a existência de correlação extremamente significante entre os parâmetros estudados (Tabela 9) (Gráfico 6).

A mediana relativa às quantidades de $\mathrm{UFC} / \mathrm{mL}$ de leite observadas nas amostras estudadas foi de $550 \mathrm{UFC/mL}$ (valor mínimo 50, valor máximo 6000) para as amostras com isolamento de Corynebacterium spp.; $500 \mathrm{UFC} / \mathrm{mL}(0-50000)$ para as amostras com isolamento de Staphylococcus spp. e 11000 UFC/mL (4,8 106000) para as amostras com isolamento de Streptococcus spp. (Tabela 10). 
Tabela 10 - Comparação entre o número de unidades formadoras de colônia por mL (UFC/ml) nas amostras de leite de fêmeas bubalinas com isolamento de Staphylococcus spp., Streptococcus spp. e Corynebacterium spp. - São Paulo - 2004

\begin{tabular}{lcccc}
\hline & No $^{\mathbf{0}}$ & Mediana & Mínima & Máxima \\
\hline Staphylococcus spp. & 31 & 500 & 0 & 50000 \\
Corynebacterium spp. & 19 & 550 & 50 & 6000 \\
Streptococcus spp. & 08 & 1100 & 4,8 & 106000 \\
\hline
\end{tabular}

Considerando a quantidade de unidades formadoras de colônia/mL e o agente isolado nas amostras estudadas, não foi encontrada diferença estatisticamente significativa para as quantidades de UFC/mL observadas nas amostras de leite com isolamento de Staphylococcus spp., Streptococcus spp. e Corynebacterium spp. (Tabela 10).

Analisando a contagem total de células somáticas e a quantificação das UFC/mL observadas nas 262 amostras de leite estudadas, foi obtido um coeficiente de correlação de Spearman igual a 0,5371, $\mathrm{P}<0,0001$, demonstrando a existência de uma correlação significante entre esses parâmetros. Nas amostras de leite com isolamento de Staphylococcus spp., analisando a relação entre a contagem total de células somáticas e a quantificação das UFC/mL, foi obtido um coeficiente de correlação de Spearman igual a 0,4404, $P=0,0066$, demonstrando a existência de uma correlação considerada muito significativa entre esses parâmetros. Nas amostras de leite com isolamento de Streptococcus spp., analisando a relação entre a contagem total de células somáticas e a quantificação das UFC/mL, foi obtido um coeficiente de correlação de Spearman igual a 0,2857, $p=0,2504$, demonstrando que 
não há correlação significativa entre esses parâmetros. Nas amostras de leite com isolamento de Corynebacterium spp., analisando a relação entre a contagem total de células somáticas e a quantificação das UFC/mL, foi obtido um coeficiente de correlação de Spearman igual a 0,2558, p=0,1452, demonstrando a inexistência de uma correlação estatística entre esses parâmetros (Tabela 11).

Tabela 11 - Comparação entre número de unidades formadoras de colônias por mililitro (UFC/ml) e contagem total de células somáticas por mililitro (CCS $/ \mathrm{ml})$ nas amostras de leite de fêmeas bubalinas segundo o resultado da análise microbiológica - São Paulo - 2004

\begin{tabular}{lccc}
\hline Análise microbiológica & No $^{\mathbf{2}}$ & UFC & CCS \\
\hline Staphylococcus spp. & 31 & $500^{\mathrm{a}}$ & 8500 \\
Corynebacterium spp. & 19 & 11000 & 9600 \\
Streptococcus spp. & 08 & 550 & 10350 \\
\hline
\end{tabular}

$a=$ coeficiente de correlação de Spearman $r=0,4404$ para $\mathrm{P}=0,0066$. 
DISCUSSÃO 


\section{DISCUSSÃO}

Vianni et al. (1990), com o objetivo de avaliar a eficiência do CMT na estimativa do número de células somáticas do leite bubalino, examinaram 159 quartos de glândulas mamárias de 40 búfalas das raças Murrah, Jafarabadi e Mediterrânea, obtendo $8,8 \%$ de quartos positivos e $91,2 \%$ de quartos negativos ao CMT.

Ramachandraiah, Kumar e Sreemannarayana (1998), avaliaram o leite dos quartos mamários de 85 búfalas da raça Murrah através do CMT e da análise microbiológica, encontrando $53 \%$ dos animais positivos e $47 \%$ negativos ao CMT. Nos animais positivos ao CMT, $48 \%$ dos quartos foram afetados.

Em um estudo realizado em propriedades situadas no Vale do Ribeira e na região de Sorocaba, Guido et al. (1994) avaliaram 250 amostras de leite de 92 fêmeas bubalinas através do CMT e exame microbiológico, encontrando $30,4 \%$ dos animais positivos e $69,6 \%$ dos animais negativos ao CMT.

O presente trabalho avaliou amostras de leite de 262 quartos mamários de fêmeas bubalinas; no teste do tamis, uma $(0,4 \%)$ amostra apresentou resultado $3+\mathrm{e}$ $261(99,6 \%)$ amostras apresentaram resultado negativo, o que demonstra uma freqüência de mastite clínica muito baixa (Gráfico 1). Considerando-se o CMT, 252 $(96,2 \%)$ amostras apresentaram reação negativa e 10 (3,8\%) reação positiva ao teste (Tabela 2) (Gráfico 3). Com base no teste de tamis e no CMT, $0,4 \%$ das amostras apresentaram mastite clínica; 3,4\% subclínica e 96,2\% ausência de mastite (Gráfico 4). Verifica-se, portanto, que os resultados são semelhantes aos 
obtidos pelos autores citados acima e que a porcentagem de mastite subclínica apresenta freqüência baixa nos rebanhos estudados.

Ramachandraiah, Kumar e Sreemannarayana (1998), realizaram CMT das amostras de leite de cada quarto da glândula mamária de 85 fêmeas bubalinas da raça Murrah. As amostras positivas ao CMT foram colhidas, centrifugadas e foi realizada a análise microbiológica do sedimento obtido. $53 \%$ dos animais foram positivos ao CMT; nesses, $82(48 \%)$ quartos mamários foram afetados. Nas 82 amostras positivas ao exame microbiológico, isolou Streptococcus spp. (46,34\%); Staphylococcus spp. (34,15\%), Corynebacterium spp. (8,55\%), Pseudomonas spp. (3,66\%), Diplococcus spp. (2,43\%), fungos (2,43\%), Streptococcus spp. associado a Diplococcus spp. $(1,22 \%)$ e Staphylococcus spp. associado a Diplococcus spp.. Os autores atribuíram a diferença nos microrganismos à variação de agentes etiológicos entre os rebanhos, devido às condições geográficas e de manejo diferentes. Detectaram também um número muito pequeno $(2,44 \%)$ de infecções mistas e $97,66 \%$ de amostras positivas ao exame microbiológico com isolamento de um único agente etiológico.

Tijare at al. (1999) avaliaram 467 amostras de leite de 119 fêmeas bubalinas pertencentes a propriedades particulares e do governo de Jabalpur, na İndia. Foram realizados vários testes indiretos a fim de comparar a eficiência na detecção de mastite sub-clínica, como teste de eletrocondutibilidade, CMT modificado, White Side moficado, entre outros; tendo sido realizada também análise microbiológica das amostras. Os autores referiram índice de $26,77 \%$ de quartos mamários positivos no exame microbiológico, onde foram isolados Staphylococcus spp. (38,99\%); Bacillus spp. (18,24\%); Escherichia coli (18,24\%), Klebsiella spp. (11,3\%); Corynebacterium $\operatorname{spp}(6,29 \%)$ e Streptococcus spp $(3,78 \%)$. 
D’apice et al. (1996) trabalharam com rebanhos bubalinos da região de Campânia na Itália, com a finalidade de padronizar um método citofluorimétrico para a identificação no leite de anticorpos específicos para Staphylococcus aureus, agente causador de mastite de maior ocorrência naquela região, segundo Fenizia et al. (1988 apud D’APICE et al., 1996, p. 179). Em seu trabalho, D’ápice et al., (1996) isolaram Staphylococcus aureus, Streptococcus agalactie e Escherichia coli do leite da fêmeas bubalinas avaliadas.

No presente trabalho foram observadas $24,4 \%$ amostras positivas e $75,6 \%$ de amostras negativas ao exame microbiológico (Tabela 3); índice semelhante ao obtido pelos autores Tijare at al. (1999). Nas $24,4 \%$ amostras positivas deste estudo foram isolados Staphylococcus spp (11,8\%); Corynebacterium spp. (7,25\%); Streptococcus spp. (3,0\%); Streptococcus spp. e Corynebacterium spp. associados $(0,4 \%)$; Corynebacterium spp. e Staphylococcus spp. associados $(0,4 \%)$; Staphylococcus spp. e Streptococcus spp. associados $(1,15 \%)$ e Staphylococcus spp, Streptococcus spp. e Corynebacterium spp. associados $(0,4 \%)$, o número de amostras negativas é estatisticamente maior do que o de amostras positivas ao exame microbiológico $(\mathrm{P}<0,0001)$ (Tabela3). Nas amostras positivas ao exame microbiológico, o número de amostras nas quais foram isolados Corynebacterium spp. e Staphylococcus spp. foi estatisticamente maior $(P<0,0001)$ (Tabela 3). Na análise microbiológica deste estudo, foram observadas $58(97,7 \%)$ amostras nas quais foi isolado um único agente e 06 amostras onde foi detectada uma associação de microrganismos (Gráfico 5), resultado muito semelhante ao referido por Ramachandraiah, Kumar e Sreemannarayana (1998).

Guido et al. (1994) avaliaram 250 amostras de fêmeas bubalinas pertencentes a propriedades no Estado de São Paulo. Das amostras avaliadas, 29,6\% foram 
positivas ao exame microbiológico; destas, em $77 \%$ foram isolados Staphylococcus spp., em 12,2\% Corynebacterium spp.; 5,4\% Escherichia coli; 4\% Streptococcus spp. e em 1,3\% Bacillus spp. Em $69,7 \%$ dos animais não foi identificado processo inflamatório, mas $18,4 \%$ desses animais apresentaram crescimento de microrganismos. Segundo os autores, as condições de higiene estão intimamente relacionadas com a saúde dos bubalinos, uma vez que microrganismos patogênicos ambientais representam o principal agente causador de mastites nesta espécie; a presença de grande número de animais $(18,4 \%)$ que apresentaram infecção na glândula mamária sem contudo apresentarem processo inflamatório constitui um fator de importância nesta espécie, uma vez que a disseminação dos agentes e a contaminação do leite é facilitada.

Os resultados neste estudo diferem dos obtidos por Guido et al. (1994), uma vez que os microrganismos isolados do leite das fêmeas bubalinas estudadas são, em sua totalidade, agentes considerados contagiosos, não tendo sido isolados microrganismos classificados como ambientais. Diante do apresentado, nas propriedades que serviram de base para a realização deste trabalho, outros fatores além dos enumerados por Guido et al. (1994) devem ser ressaltados. Fatores que propiciem a disseminação de agentes patogênicos a partir de animais portadores e entre os animais do rebanho, bem como os fatores que permitam a transmissão cruzada entre homens e animais, ressaltando a importância desses patógenos como fontes de transmissão de zoonoses. Neste trabalho, nas 231 amostras que apresentaram resultado negativo ao $\mathrm{CMT}$, foram isolados microrganismos em 50 amostras $(21,6 \%)$. Esse dado reforça o fato de que existem animais que, mesmo sendo submetidos à métodos de diagnóstico utilizados rotineiramente como meios triagem nas propriedades de produção leiteira, podem albergar agentes 
potencialmente causadores de mastite e de zoonoses. Os cuidados no transporte e no armazenamento do leite e seus derivados devem ser devidamente ressaltados, uma vez que essas etapas são muito importantes na manutenção da qualidade e na diminuição do risco que esse produtos possam representar à saúde da população que participa ativamente da cadeia de produção ou que participa apenas como consumidor final dos mesmos.

Silva et al. (1996) referem que a maioria dos quartos mamários de búfalas afetados subclinicamente não produzem crescimento bacteriano na cultura microbiológica

Segundo Schalm e Noorlander (1957), o CMT é um indicador do estado de inflamação do úbere, e não fornece informações a respeito da sua causa. Pode ocorrer que no exame microbiológico não sejam isolados patógenos no leite que é positivo no CMT (SCHALM et al., 1975).

Considerando os resultados do exame microbiológico e do CMT das amostras de leite de fêmeas bubalinas avaliadas no presente trabalho, encontramos nas 231 amostras que apresentaram resultado negativo ao CMT, isolamento de microrganismos em 50 delas. Nas 31 amostras que apresentaram resultados positivos ao CMT, 14 apresentaram crescimento de microrganismos e 17 foram negativas ao exame microbiológico (Tabela 4), o que confirma o referido pelos autores acima citados. Contudo, a freqüência de quartos negativos no CMT e com isolamento microbiológico foi maior estatisticamente $(P<0,05)$ do que a frequência de quartos positivos no CMT e com isolamento de microrganismos. Nos quartos negativos no CMT e sem isolamento de microrganismos, a freqüência foi estatisticamente maior $(P<0,05)$ do que a freqüência de quartos positivos no CMT e sem isolamento(Tabela 4). 
Tijare et al. (1999) isolou nos 33,99\% de Staphylococcus spp., sendo 2,5\% S. aureus e $36,48 \%$ coagulase negativo.

Nas amostras de leite com crescimento de microrganismos, foram identificadas neste trabalho as seguintes espécies: Staphylococcus spp. (S. hominis, S. epidermidis, S. cohnei, S. schleiferi, S. ntermedius, S. hyicus), Streptococcus spp. (S. dysgalactiae, S. agalactiae), Corynebacterium spp. (C. bovis, C. xerosis).

A mediana do número total de células somáticas em bovinos foi de 583872 células/mL (0 - 29180000) de leite, segundo Costa (2003).

Ranucci et al. (1988) utilizaram 160 amostras de leite sem alteração macroscópica aparente, de 40 fêmeas bubalinas que não apresentavam modificações ao exame de inspeção e palpação da glândula mamária. Foi realizada a contagem de células segundo o método de Breed, sendo os resultados agrupados sob a forma de um escore. Os níveis de cloro, lactose e N-acetyl-B-Dglucosaminidase foram avaliados, com a finalidade de comparar essas provas de diagnóstico indireto com diversas contagens celulares em amostras de leite de búfalas. A contagem total de células somáticas foi: inferior a 500000/mL $(78,75 \%)$; 500000 - 750000/mL (4,37\%); 750000 - 1500000/mL (9,37\%); 1500000 $5000000 / \mathrm{mL}(5,62 \%)$; superior a $5000000 / \mathrm{mL}(1,87 \%)$.

A contagem total de células somáticas das 262 amostras avaliadas neste estudo apresentou mediana de 2300 células/mL de leite (valor mínimo 100 - valor máximo 630900) (Tabela 5). O número de células polimorfonucleares e mononucleares, nas 262 amostras avaliadas, apresentou mediana de 700 células $/ m L(0-603500)$ e 1500 células $/ m L(0-178000)$, respectivamente, sendo que o número de células mononucleares é estatisticamente maior que o de 
polimorfonucleares $(\mathrm{P}<0,0001) \quad($ Tabela 5$)$. Comparando os tipos celulares encontrados nas amostras, observou-se valores maiores de células mononucleares, caracterizando predomínio de processos inflamatórios crônicos nos quartos mamários das fêmeas bubalinas avaliadas neste trabalho, o que é confirmado pelo trabalho de Della Libera (2002).

No presente estudo, considerando as 262 amostras avaliadas, a mediana do número de UFC/mL foi $0(0-475000)$ (Tabela 5). Como a maioria das amostras foram negativas ao exame microbiológico, ocorreu uma "diluição" das amostras positivas, o que levou a uma diminuição no número de microrganismos no leite.

Vianni et al. (1990) avaliaram 159 quartos de glândulas mamárias de 40 búfalas das raças Murrah, Jafarabadi e Mediterrânea, com o objetivo de avaliar a eficiência do CMT frente à contagem de células somáticas realizada segundo Broadhurst e Paley, (1939), na estimativa do número de células somáticas do leite desta espécie. Os autores encontraram contagens inferiores a 500000 células $/ \mathrm{mL}$ de leite em 95\% das amostras e observaram uma concordância elevada (93,7\%) entre os resultados obtidos no CMT e nas contagens de células na detecção de formas subclínicas da mastite de fêmeas bubalinas.

Em bovinos, as contagens de células somáticas nas amostras negativas ao exame microbiológico obtiveram mediana de 19355 células/ml para CMT negativo (COSTA, 2003).

Della Libera (2002) encontrou mediana de 13000 e 18000 células $/ \mathrm{mL}$, respectivamente, em contagem automática realizada com contador eletrônico infravermelho e contagem por microscopia óptica, técnica de Prescott e Breed. 
Silva e Silva (1994), estudando amostras de leite de fêmeas bubalinas negativas ao CMT e utilizando um hemocitômetro, obtiveram contagens de células somáticas de 50000 a 375000/mL com média de 140000 células/mL.

A contagem total de células somáticas nas amostras negativas ao exame microbiológico obteve neste estudo, uma mediana de 1900 células/mL de leite (valor mínimo 100 - valor máximo 169300), portanto muito menor do que os valores referidos pelos autores citados acima para a espécie bubalina.

Segundo Della Libera (2002), como a celularidade do leite de búfalas foi considerada pequena, muitas vezes o número de células contadas nos 100 campos do microscópico e no volume determinado pela técnica de Prescott e Breed, não representaria a realidade. No entanto, avaliado o sedimento ressuspendido e citocentrifugado das amostras de leite de búfalas, foi encontrado maior número de células mononucleares do que na contagem de células somáticas realizada pelo método anterior.

Considerando as amostras nas quais foram isolados microrganismos, a mediana das contagens totais de células somáticas apresentou valor de 8500 células/mL (1000 - 328800) nas amostras onde Staphylococcus spp. foi isolado; 10350 células/mL (1700 - 65800) nas amostras onde Streptococcus spp. foi isolado e 9600 células/mL (700 - 630900) nas amostras onde Corynebacterium spp. foi isolado (Tabela 6). O que demonstra que os resultados foram semelhantes aos observados por Vianni et al. (1990), e que os valores das contagens de células somáticas nas amostra negativas ao exame microbiológico são muito mais baixas do que as contagens de bovinos. 
Segundo Costa (2003), em bovinos, as contagens de células somáticas foram estatisticamente menores nas amostras negativas no exame microbiológico do que as contagens das amostras que apresentaram crescimento de Streptococcus spp., para CMT negativo (COSTA, 2003).

As quantidades totais de células somáticas $/ \mathrm{mL}$ nas amostras negativas ao exame microbiológico foram estatisticamente menores do que as quantidades totais de células $/ \mathrm{mL}$ das amostras que apresentaram crescimento de microrganismos. As contagens totais de células somáticas das amostras onde não houve crescimento de microrganismos diferiram significativamente das contagens das amostras nas quais foi isolado Staphylococcus spp. $(P<0,001)$; Streptococcus spp. $\quad(P<0,01)$ e Corynebacterium spp. $(\mathrm{P}<0,001)$. Comparando as amostras que apresentaram crescimento de Staphylococcus spp., Streptococcus spp. e Corynebacterium spp. não houve diferença significante estatisticamente nas quantidades totais de células somáticas $/ \mathrm{mL}$ de leite $(P>0,05)$ (Tabela 6$)$, o que difere do encontrado em bovinos por Costa (2003), onde cada agente se caracteriza por influenciar a contagem de maneira diferente..

Nas amostras negativas ao exame microbiológico, o número de células polimorfonucleares apresentou mediana de 600 células $/ \mathrm{mL}$ de leite (valor mínimo 0 valor máximo 61300). Em amostras nas quais foram isolados microrganismos, a mediana das quantidades de células polimorfonucleares foram de 4800 células $/ \mathrm{mL}$ (300 - 603500) para Corynebacterium spp.; 4500 células polimorfonucleares (300 274100) para Staphylococcus spp. e 6850 células polimorfonucleares (700 - 38600) para Streptococcus spp. (Tabela 7).

Considerando a quantidade de células polimorfonucleares e o resultado do exame microbiológico nas amostras analisadas, observamos neste trabalho que, 
naquelas em que não houve crescimento de microrganismos, o número de células polimorfonucleares apresentou valores estatisticamente menores do que nas amostras em que foram isolados Corynebacterium spp. $(\mathrm{P}<0,001)$, Staphylococcus spp. $(\mathrm{P}<0,001)$ e Streptococcus spp. $(\mathrm{P}<0,001)$ (Tabela 7).

O número de células polimorfonucleares nas amostra de leite com isolamento de Staphylococcus spp., Streptococcus spp. e Corynebacterium spp. não apresentou valores estatisticamente significantes $(P>0,05)$ (Tabela 7).

As amostras negativas ao exame microbiológico apresentaram mediana de 1150 células mononucleares/mL de leite (valor mínimo 0 , valor máximo 108000); as amostras com isolamento de Corynebacterium spp., 4800 células mononucleares/mL (400 - 27400); as amostras com isolamento de Staphylococcus spp. 4600 células mononucleares/mL (600 - 178000) e as amostras com isolamento de Streptococcus spp., 3700 células mononucleares/mL (1000 - 29500) (Tabela 8).

Nas amostras negativas ao exame microbiológico, a quantidade de células mononucleares estimada foi estatisticamente menor do que nas amostras com isolamento de Corynebacterium spp. e Staphylococcus spp. $(P<0,001)$ e na amostras com isolamento de Streptococcus spp. $(\mathrm{P}<0,01)$ (Tabela 8).

Não houve diferença estatisticamente significante quando foram comparadas as quantidades de células mononucleares obtidas nas amostras em que foram isolados Corynebacterium spp., Staphylococcus spp. e Streptococcus spp. $(\mathrm{P}>0,05)$.

Em bovinos, segundo Costa, (2003) há predominância de células polimorfonucleares quando são isolados Staphylococcus spp e Streptococcus spp..

Nas amostras de leite em que Staphylococcus spp. foi isolado, não foi determinada diferença estatisticamente significante entre as quantidades de células polimorfonucleares e células mononucleares. O coeficiente de correlação de 
Spearman relativo às quantidades de células polimorfonucleares e mononucleares nas amostras de leite com isolamento de Staphylococcus spp foi de 0,8930 e $P<0,0001$, demonstrando a existência de correlação extremamente significante entre os parâmetros estudados (Tabela 9). Nas amostras de leite em que Streptococcus spp. foi isolado, não foi determinada diferença estatisticamente significante entre as quantidades de células polimorfonucleares e células mononucleares. $O$ coeficiente de correlação de Spearman relativo às quantidades de células polimorfonucleares e mononucleares nas amostras de leite com isolamento de Streptococcus spp foi de 0,8333 e $P=0,0077$, demonstrando a existência de correlação muito significativa entre os parâmetros estudados (Tabela 9). Este trabalho concorda, portanto concorda com Vianni (1990) que encontrou valores abaixo de 500000células $/ \mathrm{mL}$, pois as mastites predominantes eram crônicas.

Nas amostras de leite em que Corynebacterium spp. foi isolado, não foi determinada diferença estatisticamente significante entre as quantidades de células polimorfonucleares e células mononucleares.O coeficiente de correlação de Spearman relativo às quantidades de células polimorfonucleares e mononucleares nas amostras de leite com isolamento de Corynebacterium spp. foi de 0,9236 e $P<0,0001$, demonstrando a existência de correlação extremamente significante entre os parâmetros estudados (Tabela 9). Considerando que não houve difrença significativa entre o número de células PMN e MN nas amostras com isolamento de Staphylococcus spp, o que caracteriza processos inflamatórios crônicos, ssas contagens baixas justificam-se pela cronicidade dos processos.

Na Itália, Fantuz et al. (1998), utilizando amostras de leite de oito fêmeas bubalinas realizaram a contagem de células somáticas através de um hemocitômetro.Os autores afirmaram que as fêmeas bubalinas da raça Mediterrânea 
têm uma contagem de células somáticas mais baixa do que a do leite de bovinos; foram referidos valores da ordem de $10^{6}$ células somáticas $/ \mathrm{mL}$ de leite.

Dhakal, Kapur e Bhardwaj (1991), avaliaram amostras de leite de cada quarto mamário de 50 fêmeas bubalinas e realizaram a contagem de células somáticas de acordo com Schalm, usando a coloração de Newman-Lampert.. Observaram que amostras colhidas durante o processo de ordenha possuíam uma contagem de células somáticas maior em leite normal $(1,2 \times 106 / \mathrm{mL})$ e mastítico $(3,2 \times 106 / \mathrm{mL})$ quando comparadas às amostras colhidas no início da ordenha $(0,096 \times 106 / \mathrm{mL}$ e 2,3 $\mathrm{x} 106 / \mathrm{mL}$ ).Segundo os autores, as amostras colhidas durante o processo de ordenha apresentaram um número maior de células quando comparadas às amostras colhidas no início, devido à liberação das células polimorfonucleares e das células epiteliais dos alvéolos das glândulas à medida que cai a pressão do leite durante a ordenha.

No presente trabalho, a colheita das amostras de leite foram realizadas no início da ordenha, minimizando assim, segundo os autores citados anteriormente, a elevação do número de células devido à maior descamação do epitélio na fase final da ordenha.

Em bovinos, a quantificação de UFC/mL em 506 amostras de leite obteve uma mediana de 6750 UFC/mL (COSTA, 2003).

Vieira, et al. (1994) realizaram análise microbiológica e determinação do número total de UFC/mL de leite em amostras de 16 fêmeas bubalinas, mantidas sob diferentes condições higiênicas. Encontraram valores de 673,68 UFC/mL nos animais controle, que não sofreram nenhum tipo de tratamento higiênico; 253,24 UFC/mL nos animais em que o úbere era lavado com água morna; 388,68 UFC/mL nos animais que passavam dentro de um tanque artificial para se banharem e 38,24 
UFC/mL nos animais que após passarem pelo tanque eram lavados com uma solução bactericida, que reduziu substancialmente a carga de contaminantes no leite. Observaram um aumento significativo no número de UFC/mL nos meses mais chuvosos do ano (dezembro a maio).

Neste trabalho, a mediana relativa às quantidades de UFC/mL de leite observadas nas amostras estudadas foi de 550 UFC/mL (valor mínimo 50, valor máximo 6000) para as amostras com isolamento de Corynebacterium spp.; 500 UFC/mL (valor mínimo 0, valor máximo 50000) para as amostras com isolamento de Staphylococcus spp. e 11000 UFC/mL (valor mínimo 4,8, valor máximo 106000) para as amostras com isolamento de Streptococcus spp. (Tabela 10). O número de UFC encontrado em bubalinos é inferior ao de bovinos, para qualquer um dos agentes isolados.

No presente estudo, considerando a quantidade de unidades formadoras de colônia/mL e o agente isolado nas amostras de leite de fêmeas bubalinas estudadas, não foi encontrada diferença estatisticamente significativa para as quantidades de UFC/mL observadas nas amostras de leite com isolamento de Staphylococcus spp., Streptococcus spp. e Corynebacterium spp. Portanto, em bubalinos, diferentemente do que ocorre em bovinos e para os microrganismos isolados neste trabalho, não é possível determinar um agente específico que pudesse ser evidenciado com a finalidade de direcionar o tratamento a determinados animais e assim obter uma diminuição significativa da contagem total de células somáticas.

De acordo com a instrução normativa n51 do Ministério da Agricultura de 18/09/2002, o leite cru refrigerado tipo B integral, pode possuir níveis de até $5 \mathrm{x}$ $10^{5} \mathrm{UFC} / \mathrm{mL}$. Assim sendo, de acordo com os resultados deste trabalho, o leite de búfala aprsenta valores muito aquém do estabelecido. 
Houve correlação entre os números de unidades formadoras de colônias por $\mathrm{mL}$ e a contagem de células somáticas por $\mathrm{mL}$, porém, devido ao índice de correlação baixo pode-se concluir que outros fatores tais como fase de lactação, alimentação, entre outros, estão interferindo nos dados observados.

A quantidade de UFC/mL no leite de fêmeas bubalinas foi pequena, principalmente quando comparada aos valores encontrados em bovinos, deve-se ressaltar o risco que o leite contaminado pode representar risco de Saúde Pública, quando levamos em conta as condições inadequadas de transporte e armazenamento a que o muitas vezes o produto está sujeito, o que potencializa, de maneira muito importante, seu papel como fonte de infecção de diversas zoonoses, sem contar o prejuízo econômico decorrente das perdas associadas ao processo, nas diversas etapas da cadeia produtiva, bem como no impacto social que representa, sobretudo às camadas mais pobres da população e portanto, mais necessitadas e carentes de atenção e apoio. Deve-se ressaltar o potencial formador de opinião e de agente modificador e de fomento à produção que a categoria médico veterinária representa em nossa sociedade. Cabe a nós tomarmos consciência da importância fundamental da nossa categoria, principalmente junto à camada produtiva da sociedade e assim, diante da crescente projeção que o agronegócio assume na economia do país, assumirmos nossa participação nesse processo. 


\section{CONCLUSÕES}




\section{CONCLUSÕES}

- A freqüência de mastite subclínica nos rebanhos estudados foi muito baixa.

- A freqüência de quartos negativos no CMT e com isolamento microbiológico foi maior estatisticamente $(P<0,05)$ do que a freqüência de quartos positivos no CMT e com isolamento de microrganismos; este dado indica que há elevada freqüência de portadores ou que o teste de CMT não é um bom teste de triagem para mastite em bubalinos.

- Nas amostras em que houve isolamento de microrganismos não se verificou diferença entre as contagens de células polimorfonucleares e mononucleares, tanto para Staphylococcus spp., Streptococcus spp. e Corynebacterium spp., caracterizando a presença de processo inflamatório crônico para todos os agentes isolados.

- Houve correlação entre os números de unidades formadoras de colônias por $\mathrm{mL}$ e a contagem de células somáticas por $\mathrm{mL}$, porém devido ao índice de correlação baixo pode-se concluir que outros fatores tais como fase de lactação, alimentação, entre outros, estão interferindo nos dados observados.

- As baixas contagens de unidades formadoras de colônias por $\mathrm{mL}$ indicam que há pouca contaminação do leite, porém se as condições de resfriamento e transporte não forem adequadas, pode haver comprometimento do produto para consumo humano e conseqüente risco à saúde pública. 
REFERÊNCIAS 


\section{REFERÊNCIAS ${ }^{1}$}

BADINI, K. B. Estudo das características físico-químicas, microbiológicas e dos hábitos de consumo do leite cru comercializado clandestinamente nos municípios de Botucatu/SP e São Manuel/SP, 1993. 1995. 124 f. Dissertação (Mestrado em Medicina Veterinária Preventiva) - Faculdade de Ciências Agrárias e Veterinárias, Universidade Estadual Paulista, Jaboticabal, 1995.

BARUSELLI, P. S. L'allevamento bufalino in Brasile. Bubalus Bubalis, n. 5, p. 7$11,1995$.

BENITES, N. R.; MELVILLE, P. A.; COSTA, E. O. Modificação da técnica de contagem de células somáticas de Prescott e Breed utilizando-se a coloração de Hematoxilina e Eosina. NAPGAMA, v. 4, n. 3, p. 6-9, 2001.

BHATIA, K. L.; VALSA, C. Lactoferrin level in buffalo milk. In: WORLD BUFALO CONGRESS, 4., 1994, São Paulo. Proceedings... São Paulo: Associação Brasileira de Criadores de Búfalos, 1994. v. 2, p. 162.

BLOOD, D. C.; RADOSTOSIS, O. M. Veterinary medicine. 7. ed. London: Baillière Tindall, 1991. p. 501-59.

COSTA, E. O.; BENITES, N. R.; MELVILLE, P. A.; PARDO, R. B.; RIBEIRO, A. R.; WATANABE, E. T. Estudo etiológico da mastite clínica bovina. Revista Brasileira de Medicina Veterinária, v. 17, n. 4, p. 156-158, 1995.

COSTA, S. S. Comparação entre a quantidade de unidades formadoras de colônias de microrganismos e a contagem de células somáticas em amostras de leite provenientes de glândulas mamárias de bovinos com infecção intramamária. 2003. 83 f. Dissertação (Mestrado em Epidemiologia Experimental e Aplicada às Zoonoses) - Faculdade de Medicina Veterinária e Zootecnia, Universidade de São Paulo, São Paulo, 2003.

\footnotetext{
${ }^{1}$ Conforme as diretrizes para a apresentação de dissertações e teses na Faculdade de Medicina Veterinária e Zootecnia da Universidade de São Paulo. 4. ed. São Paulo: FMVZ-USP 2003. 84 p.
} 
CRAVEN, N.; WILLIAMS, M. R. Defenses of the bovine mammary gland against infection and prospects for their enhancement. Veterinary Immunology and Immunopathology, v. 10, p. 71-127, 1985.

D’ÁPICE, L.; FENIZIA, D.; CAPPARELLI, R.; SCALA, F.; IANELLI, D.Detection of antibodies to Staphylococcus aureus in water buffalo milk by flow cytometry. Research in Veterinary Science, v. 60, p. 179-181, 1996.

DE FRANCISCIS, G.; DI PALO, R. Buffalo milk Production. In: WORLD BUFALO CONGRESS, 4., 1994, São Paulo. Proceedings... São Paulo: Associação Brasileira de Criadores de Búfalos, 1994. v. 1, p. 137.

DELLA LIBERA. A. M. M. P. Características físico - químicas e microbiológicas do leite de vacas com alta contagem de células somáticas. 1998. 79 f. Dissertação (Mestrado e Clínica Médica) -- Faculdade de Medicina Veterinária e Zootecnia, Universidade de São Paulo, São Paulo.

DELLA LIBERA. A. M. M. P. Avaliação dos fagócitos no leite de búfalas (Bubalus bubalis) hígidas criadas no Estafo de São Paulo. 2002. 125 f. Tese (Doutorado em Clínica Médica) - Faculdade de Medicina Veterinária e Zootecnia, Universidade de São Paulo, São Paulo, 2002.

DHAKAL, I. P.; KAPUR, M. P.; BHARDWAJ, R. M. Diagnosis of subclinical mastitis in buffaloes using somatic and viable cell counts. Indian Journal Dairy Science, v. 44, n. 9 , p. 585-586, 1991.

DU PREEZ, J. H.; GIESECKE, W. H. Mastitis. In: COETZER, J. A. W.; THOMPSON, G. R.; TUSTIN, R. C. Infectious diseases of livestock. London: Oxford University Press, 1994. v. 2, p. 1564-1595.

FANTUZ, F.; BALDI, A.; DELL'ORTO, V.; POLIDORI, F.; ROSSI, C. S.; POLITIS, I.; HEEGAARD, C. W. Distribution of plasminogen activator forms in different fractions of buffalo milk. Journal of Dairy Research, v. 65, p. 521-527, 1998.

FAO. Faostat agriculture data (Agricultural production - live animals - livestock ). Disponível em: <http://apps.fao.org>. Acesso em: 03 jul. 2003. 
GUIDO, M. C.; CARVALHO, N. A. T.; BARUSELLI, P. S.; COSTA, E. O. Female bubaline mastitis etiology in brazilian state of São Paulo. In: CONGRESSO NAZIONALE SULL ÁLLEVAMENTO DEL BÚFALO,1., 1994 Trabalhos apresentados... S.I.: s.n., 1994. 1 CD-ROM.

GRAPHPAD INSTAT. Statistical analysis systems for personal computers. S. I., 1990-1993. Software.

IBGE. Banco de dados agregados - Sistema IBGE de recuperação automática SIDRA. Disponível em: <http://www.sidra.ibge.gov.br>. Acesso em: 03 jul. 2003.

KRIEG, N, R.; HOLT, J. C. Bergey's manual of systematic bacteriology. 9. ed. Baltimore: Willians \& Wilkins, 1994. 2298 p.

KUMAR, P.; THAKUR, D. K. Comparative efficacy of indirect tests for the detection of mastitis in buffaloes. Indian Veterinary Journal, v. 78, p. 801-803, 2001.

KUMAR, R.; BATHIA, K. L. Lactoperoxidase activity in buffalo milk and whey. In: WORLD BUFALO CONGRESS, 4., 1994, São Paulo. Proceedings... São Paulo: Associação Brasileira de Criadores de Búfalos, 1994. v. 2, p. 168.

LÁU, H. D. Important economic diseases in buffaloes. In: WORLD BUFFALO CONGRESS, 4., São Paulo, 1994, Anais... São Paulo: Associação Brasileira de Criadores de Búfalos, 1994. p. 209-220.

LENNETTE, E. H.; BALOWS, A.; HANSLER JR, W. J.; SHADOMY, H. J. Manual of clinical microbiology. 4. ed. Washington: American Society for Microbiology Press, 1985. $1149 \mathrm{p}$.

MURRAY, P. R.; BARON, E. J.; PFALLER, M. A.; TENOVER, F. C.; YOLKEN, R. $\mathrm{H}$. Manual of clinical microbiology. 7. ed. Washington: American Society for Microbiology. 1999. 1773 p.

NAG, N. C. Staphylococcal mastitis in cows, buffaloes and goats and their antibiotic sensitivity. Indian Journal Animal Health, v. 14, p. 169-173, 1995. 
PAAPE, M. J. ; HAFS, H. D. ; SNYDER, W. W. Variations of estimated numbers of milk somatic cells staines with wright's stains or pyronon y methil green stain. Journal of Dairy Sciene, v. 46, n. 11, p. 1211-6, 1963.

PRESCOTT, S. C.; BREED, R. S. The determination of the number of the body cells in milk by a direct method. Journal of Infectious diseases, v. 7, p. 632-640, 1910.

RAMACHANDRAIAH, K.; KUMAR, K. M. S.; SREEMANNARAYANA, O. Subclinical mastitis in na organized buffalo farm. Buffalo Bulletin, v. 17, n. 4, p. 85-87, 1998.

RANUCCI, S.; FRUGANTI, G.; VALENTE, C.; TESEI, B.; TULLIO, S. Sul valore diagnostico di alcune prove di laboratório nella mastite subclinica della búfala. Selezione Veterinaria, v. 29, n. 3, p. 495-506, 1988.

SCHALM, O. M.; CARROLL, E. J.; JAIN, N. C. Bovine mastitis. Philadelphia: Lea \& Febiger, 1971. 360 p.

SCHALM, O. W.; NOORLANDER, D. O. Experiments and observations leading to development of California Mastitis Test. Journal of the American Veterinary Medical Association, v. 130, n. 5, p. 199-207, 1957.

SHUKLA, P. C.; SUPEKAR, P. G. Cell count in milk samples of normal ans mastitis animals. Livestock Adviser, v. 12, n. 12, p. 44-48, 1987.

SILVA, I.D.; SILVA, K.F.S.T.; AMBAGALA, A.P.N.; COORAY, R. markers of inflammation in buffalo milk. In: REGIONAL SYMPOSIUM, 1999, Peradeniya, Sri Lanka. Proceedings...Peradenya: s.n., 1999.

SILVA, I. D.; SILVA, K.F.S.T. Total and differential cell counts in buffalo (Bubalus bubalis) milk. Buffalo Journal, v.10, n. 2, p. 133-137, 1994.

TIJARE, D. B.; SINGH, A. K.; CHATURVEDI, V. K.; DHANESAR, N. S. Sensitivity of indirect tests in detection of subclinical mastitis in buffaloes. Indian Veterinary Journal, v. 76, p. 912-915, 1999. 
TIZARD, I. R. Imunologia veterinária: uma introdução. 6. ed. São Paulo: Roca, 2002, 532 p.

VALE, W. G. Prospects of buffalo production in Latin America. Panel: Water buffalo world uptake. In: WORLD BUFALO CONGRESS, 4., 1994, São Paulo. Proceedings... São Paulo: Associação Brasileira de Criadores de Búfalos, 1994. v. 1, p. 75.

VIANNI, M .C. E.; NADER FILHO, A.; ROSSETI, D. J. G.; LONGHI, J. L.; SICHER, M. Eficiência do Califórnia Mastitis Test (CMT) na estimativa do número de células somáticas do leite bubalino. Ciência Veterinária, v. 4, n. 2, p. 3-4, 1990.

VIEIRA, L. C.; LOURENÇO JUNIOR, J. B.; HUNH, S. BATISTA, H. A. M.; HANTANI, A. K. Microbiology of buffalo milk under different hygienic conditions. In: WORLD BUFALO CONGRESS, 4., 1994, São Paulo. Proceedings... São Paulo: Associação Brasileira de Criadores de Búfalos, 1994. v. 2, p. 175. 